\title{
Elemental composition of membrane foulant layers using EDS, XPS, and RBS
}

Alexander S. Gorzalski ${ }^{1}$, Carrie Donley ${ }^{2}$, Orlando Coronell ${ }^{1, *}$

${ }^{1}$ Department of Environmental Sciences and Engineering, Gillings School of Global Public Health, University of North Carolina at Chapel Hill, Chapel Hill, NC 2599, ${ }^{2}$ Chapel Hill Analytical and Nanofabrication Laboratory, University of North Carolina, Chapel Hill, NC 27599

*Corresponding author [tel:+1-919-966-9010; fax:+1-919-966-7911; e-mail: coronell @unc.edu]

Abstract: Existing studies investigating the elemental composition of membrane foulant layers typically use one of the following analytical techniques: energy-dispersive X-ray spectroscopy (EDS), X-ray photoelectron spectroscopy (XPS), or Rutherford backscattering spectrometry (RBS). However, given that EDS, XPS, and RBS have different capabilities, limitations, and depths of analysis, these techniques may provide differing results from each other. Thus, to understand the suitability of each technique for the analysis of membrane foulant layers, a thorough study is needed that compares EDS, XPS, and RBS results for a diverse set of fouled membranes. As such, the objectives of this study were to identify the strengths, weaknesses, and limitations of EDS, XPS and RBS in the characterization of the elemental composition of foulant layers, and evaluate whether the three techniques yield consistent and/or complementary results for sample composition and structure. We studied four diverse fouled membranes, each before and after cleaning, as well as the original unfouled membranes, and assessed the suitability of each technique for various applications, such as the detection of major elements in thick and thin layers, characterization of sample depth heterogeneity, evaluation of overall membrane cleaning efficacy, among others. Results show that in the analysis of membranes and foulant layers: (i) applying a single technique may lead to incomplete or incorrect conclusions about composition or structure; (ii) RBS is the most advantageous technique for elemental analysis; (iii) EDS has important limitations, but is appropriate for evaluating overall elemental composition of foulant 
layers and overall efficacy of membrane cleaning; and (iv) XPS is well-suited to detect trace elements in foulant layers and small amounts of foulants remaining on cleaned membranes. Overall, results show that the suitability of each technique depends on the research objectives.

Keywords: nanofiltration, reverse osmosis, fouling, Rutherford backscattering spectrometry, RBS, X-ray photoelectron spectroscopy, XPS, energy-dispersive X-ray spectroscopy, EDS

\section{Introduction}

Nanofiltration (NF) and reverse osmosis (RO) membranes are technologies widely used in the purification of a broad range of waters, including seawater, domestic wastewater, and wastewaters related to oil and gas production $[1,2]$. These membranes typically have a thin-film composite structure consisting of an ultrathin top polyamide active layer (20-200 nm thick), an intermediate porous support ( 20-50 $\mu \mathrm{m}$ thick), and a structural backing fabric $(\sim 50-150 \mu \mathrm{m}$ thick) [3,4]. An important operational problem in NF/RO filtration is membrane fouling, which consists of the deposition of solutes or particulates on the membrane surface or pores and results in decreased permeate water flux. Membrane fouling is impacted by, and in turn affects, treatment plant operations [5], and cannot be fully prevented despite extensive pretreatment [6]. Membrane fouling is dependent on operational parameters, source water quality, and membrane surface properties [1,5,7], which are factors that vary by site. Therefore, the design of pretreatment systems and formulation of operational strategies to minimize fouling, as well as the optimization of cleaning practices for fouled membranes, are informed by an understanding of the characteristics of the foulant layers and membrane surface on a case-by-case basis. 
Important objectives in the characterization of foulant layers and membrane surfaces are the quantification of their elemental composition, and estimation of foulant layer thickness, as these objectives allow conclusions to be drawn related to the types of foulants comprising foulant layers and the severity of fouling. Three techniques that have been used to accomplish these objectives are energy-dispersive X-ray spectroscopy (EDS) [8-12], X-ray photoelectron spectroscopy (XPS) [7,13-17], and more recently Rutherford backscattering spectrometry (RBS) [14,18-23]. EDS, XPS and RBS give, in principle, the same information about the sample analyzed, specifically its relative elemental composition. However, given that the three techniques have different depths of analysis, they have been traditionally used for different purposes in NF/RO membrane characterization. EDS probes a few microns from the sample surface [24,25], and is by far the technique that has been used the most in the characterization of the elemental composition of foulant layers [8-12], as mature foulant layers have thicknesses on the order of $\sim 1-100 \mu \mathrm{m}$ [26-29]. XPS probes less than $10 \mathrm{~nm}$ from the sample surface [30], and thus is less often used to study foulant layers [16,31-33], and more frequently used for analyzing the surfaces of unfouled membranes [7,14,34-36]. RBS probes typically $\sim 2 \mu \mathrm{m}$ from the sample surface $[19,37,38]$ and has been used to characterize active and support layers of NF/RO membranes [14,21,23,39-42], and more recently to study membrane foulant layers [38].

Given that EDS, XPS, and RBS have different capabilities, limitations, depths of analysis, and fundamental physical principles, these three techniques may provide differing (yet complementary) information on membrane samples. However, we could not find in the literature a study that compared EDS, XPS and RBS results for the characterization of the elemental composition of foulant layers or membranes. Such a comparison would allow for the 
identification of the advantages, disadvantages and limitations of each technique in the characterization of foulant layers and membranes, and the potential for using these techniques in a complementary manner.

Accordingly, the objectives of this study were to identify the strengths, weaknesses, and limitations of EDS, XPS and RBS in the characterization of the elemental composition of thinfilm composite membranes and their foulant layers, and evaluate whether the three techniques yield consistent and/or complementary information on membrane sample composition and structure. To achieve this objective we used EDS, XPS and RBS to characterize the elemental compositions of membranes prior to fouling, fouled at full-scale, and after chemical cleaning. We compared results from the three techniques to determine if foulant detection or prevalence was consistent among methods, and what additional information each technique provided about the foulant layers and membranes. We discuss the capabilities and limitations of each technique based on the results obtained and the physical principles behind each technique. Findings presented here are intended to inform the selection of foulant characterization techniques and further the understanding of the structure of foulant layers and foulants on cleaned membranes.

\section{Materials and Methods}

\subsection{Full-scale treatment facility}

Fouled membrane elements for autopsy and cleaning tests were collected from the 6-MGD groundwater NF facility operated by the Cape Fear Public Utility Authority (CFPUA) in Wilmington, NC. At the time of this study, the treatment facility operated dedicated treatment trains for waters from the Castle Hayne and Peedee aquifers. Water pretreatment before 2-stage 
nanofiltration consisted of conditioning with sulfuric acid and antiscalant (SpectraGuard, Professional Water Technologies, Vista, CA), and 5- $\mu \mathrm{m}$ cartridge prefiltration. Pressure vessels in each NF stage contained six 8-in membrane elements, with twice the number of pressure vessels in the first stage as in the second stage. Each train was operated at an overall recovery of $80 \%$ with $\approx 50 \%$ recovery in the first stage. The Castle Hayne treatment train used TFC-ULP and TFC-S membrane elements (Koch Membrane Systems, Wilmington, MA) in the first and second stages, respectively, while the Peedee train used TFC-S membrane elements in both stages. Both the TFC-ULP and TFC-S membranes have uncoated polyamide active layers as confirmed experimentally by ATR-FTIR analyses [36,43].

\subsection{Source water quality and membrane samples}

Table 1 presents the water quality for both the feed Castle Hayne and Peedee waters. Water quality parameters include turbidity, alkalinity, hardness, conductivity, $\mathrm{pH}$, concentration of various elements, dissolved organic carbon (DOC), UV absorbance at a wavelength of $254 \mathrm{~nm}$ (UVA 254), and specific UV absorbance (SUVA). The two waters had dissimilar water quality, both in terms of organic and inorganic constituents, and thus it was determined that membranes from both treatment trains warranted autopsy. For both the Castle Hayne and Peedee treatment trains, fouled membrane elements collected included the first element in stage one (CHS1, PDS1) and last element in stage two (CHS2, PDS2) (i.e., the CHS1 element was a TFC-ULP element, and all other elements were TFC-S elements). New unfouled, unused flat-sheet TFCULP and TFC-S membranes (Koch Membrane Systems), and polysulfone support membranes (Hydranautics, Oceanside, CA) were obtained from the manufacturers. 
Table 1. Feed water quality of influent to nanofiltration trains treating water from the Castle Hayne and Peedee aquifers.

\begin{tabular}{|c|c|c|}
\hline Water quality parameter & Castle Hayne $^{a}$ & Peedee \\
\hline Turbidity (NTU) & 0.088 & 0.105 \\
\hline Alkalinity (mg. $\mathrm{L}^{-1}$ as $\left.\mathrm{CaCO}_{3}\right)$ & 94.6 & 180.5 \\
\hline Hardness (mg. $\mathrm{L}^{-1}$ as $\left.\mathrm{CaCO}_{3}\right)$ & $281.4-308.2$ & $262-303$ \\
\hline Conductivity $\left(\mu \mathrm{s} . \mathrm{cm}^{-1}\right)$ & $558-570$ & $565-578$ \\
\hline $\mathrm{pH}$ & 6.0 & 6.7 \\
\hline Aluminum $^{\mathrm{b}}\left(\mathrm{mg} \cdot \mathrm{L}^{-1}\right)$ & $0.001-0.022$ & $0.002-0.019$ \\
\hline Chloride (mg. $\left.\mathrm{L}^{-1}\right)$ & $29.4-31.4$ & $51.6-60.1$ \\
\hline Calcium (mg. $\left.\mathrm{L}^{-1}\right)$ & $105.5-115.8$ & $93.5-111.7$ \\
\hline $\operatorname{Iron}\left(\mathrm{mg} \cdot \mathrm{L}^{-1}\right)$ & $4.9-6.5$ & $0.11-0.23$ \\
\hline Magnesium (mg.L $\left.{ }^{-1}\right)$ & $2.2-2.3$ & $5.9-6.9$ \\
\hline Manganese (mg.L $\left.\mathrm{L}^{-1}\right)$ & $0.08-0.09$ & $0.01-0.02$ \\
\hline Silicon $\left(m g . L^{-1}\right)$ & $14.2-20.2$ & $9.8-10.9$ \\
\hline Sodium $\left(\mathrm{mg} \cdot \mathrm{L}^{-1}\right)$ & $8.1-9.8$ & $17.3-20.7$ \\
\hline Sulfate $\left(\mathrm{mg} \cdot \mathrm{L}^{-1}\right)$ & $150-231$ & $71-103$ \\
\hline $\mathrm{DOC}\left(\mathrm{mg} . \mathrm{L}^{-1}\right)$ & $6.7-8.7$ & $3.0-5.2$ \\
\hline UVA $254\left(\mathrm{~m}^{-1}\right)$ & $13.6-38.3$ & $9.8-14.6$ \\
\hline SUVA $\left(L \cdot \mathrm{mg}^{-1} \cdot \mathrm{m}^{-1}\right)$ & 3.7 & 2.8 \\
\hline
\end{tabular}

Notes: ${ }^{a}$ The water quality of Castle Hayne water was also provided in a previous study [38]. ${ }^{b}$ Analytical error was typically greater than observed concentration.

\subsection{Membrane cleaning tests}

Fouled membrane samples were cleaned via immersion in a heated $\left(38^{\circ} \mathrm{C}\right)$ cleaning solution for one hour. The cleaning solution was prepared using sodium tripolyphosphate (STPP, 2\%) with ethylenediaminetetraacetic acid (EDTA, 0.8\%) at $\mathrm{pH}=10.5$. This cleaning solution was shown to be broadly effective at recovering specific water flux to the levels for new elements [38].

\subsection{SEM and EDS analyses}

SEM and EDS analyses were performed using a Helios Nanolab 600 dual beam system (FEI, Hillsboro, OR) equipped with an INCA X-ray microanalysis system (OXFORD Instruments, 
United Kingdom) having a Si(Li) INCA PentaFET-x3 detector. An accelerating voltage of $20 \mathrm{kV}$ and current of $0.34 \mathrm{nA}$ were used. All samples were coated with a $5 \mathrm{~nm}$ layer of gold-palladium (SEM) or gold (EDS) to prevent sample charging. EDS spectra were collected at a magnification of $300 \mathrm{X}$ and the analyzed area per sample was $0.12 \mathrm{~mm}^{2}(300 \mu \mathrm{m} \times 400 \mu \mathrm{m})$, corresponding to the largest area that the electron beam could raster over the sample surface. The analysis depth under our experimental settings was $\approx 8 \mu \mathrm{m}[44]$ assuming a density of $1.24 \mathrm{~g}_{\mathrm{cm}}^{-3}$ for polymer layers [45]. A minimum of three replicates were tested for fouled and cleaned samples and six replicates were tested for unfouled samples. Analysis of EDS spectra for quantification of elemental composition was performed with the INCA software that accompanies the instrument using the auto-identification feature that automatically detects elements present in the sample. Misidentification of elements by the auto-identification feature was controlled for by reviewing auto-detected elements. Daily energy calibration was performed using copper (tape) as a standard, and elements were compared to preloaded known standards within the INCA software (i.e., C: $\mathrm{CaCO}_{3}, \mathrm{O}: \mathrm{SiO}_{2}, \mathrm{Al}_{1} \mathrm{Al}_{2} \mathrm{O}_{3}, \mathrm{Si}: \mathrm{SiO}_{2}$, $\mathrm{S}: \mathrm{FeS}_{2}$, Ca: wollastonite $-\mathrm{CaSiO}_{3}$, $\mathrm{Fe}: \mathrm{Fe}$ ).

\subsection{XPS analyses}

XPS data were acquired using a Kratos Axis Ultra DLD system with a monochromatic Al Ka Xray source $(1,486.6 \mathrm{keV}, 150 \mathrm{~W})$, a $90^{\circ}$ take-off angle, and a $0.21 \mathrm{~mm}^{2}(300 \mu \mathrm{m} \times 700 \mu \mathrm{m})$ beam analysis area. This is the largest that can be analyzed by the instrument, and is determined by a slot shaped aperture in the path of the electrons as they travel towards the entrance optics that lead into the analyzer. A charge neutralizer was used to prevent charging and the XPS spectra were energy corrected so that the $\mathrm{C} 1 \mathrm{~s}$ line was at $284.6 \mathrm{eV}$, consistent with adsorption of adventitious carbon in the form of graphite or $\mathrm{CH}_{2}$-like carbon. High resolution $(0.1 \mathrm{eV})$ scans 
were performed for carbon (C 1s), oxygen (O 1s), nitrogen (N 1s), iron (Fe 2p), calcium (Ca 2p), silicon ( $\mathrm{Si} 2 \mathrm{p}$ ), sulfur ( $2 \mathrm{p}$ ), and aluminum ( $\mathrm{Al} 2 \mathrm{p}$ ). A minimum of three replicates were analyzed for fouled and cleaned membrane samples, and a minimum of four replicates were analyzed for unfouled membranes. All samples were vacuum-dried for $\approx 24 \mathrm{~h}$ before analysis.

\subsection{RBS analyses}

RBS analyses were performed using a $2 \mathrm{MeV}^{4} \mathrm{He}^{2+}$ beam generated by a Tandem electrostatic accelerator, a sample-detector distance of $75 \mathrm{~mm}$, and incident, exit, and scattering angles of $22.5^{\circ}, 42.5^{\circ}$, and $160^{\circ}$, respectively. The fluence of irradiation of membrane samples during RBS analyses was $5 \times 10^{13} \mathrm{He} / \mathrm{cm}^{2}$. Data analysis was performed using the commercial software SIMNRA 6.06v [46]. For each membrane type studied (e.g., fouled CHS1 membrane), we analyzed an area of $\approx 2,000 \mathrm{~mm}^{2}$ which corresponded to the largest area that could be analyzed using an average analysis time of $\approx 35$ minutes. While a detailed description of RBS data analyses methods are beyond the scope of this study, we have included in the Supplementary Material a description of the general approach used to analyze RBS data, including to obtain depth profile information. Details on RBS theory, instrumentation, and analysis to characterize membrane elemental composition can be found elsewhere [23,47].

\section{Results}

\subsection{Membrane samples of known chemical composition}

\subsubsection{Chemically depth-homogeneous sample: polysulfone support}

We used polysulfone support samples to evaluate the ability of EDS, XPS and RBS to accurately determine the elemental composition of 'thick' layers with homogeneous chemical composition, 
including that of thick homogeneous foulant layers. We use the qualifier 'thick' to refer to layers that are thicker than the analysis depth of the technique used. Table 2 lists the analysis depths of EDS, XPS and RBS, along with other technical details, benefits, and drawbacks discussed below. While polysulfone supports have a polyester backing, the polysulfone layer is much thicker $(\sim 20-50 \mu \mathrm{m})$ than the analysis depth of EDS (a few microns), XPS $(<10 \mathrm{~nm})$ and RBS $(\sim 2 \mu \mathrm{m})$, and thus can be considered chemically homogeneous in depth for EDS, XPS and RBS analyses.

Elemental composition results for polysulfone support samples (Figure 1a) show that EDS, XPS, and RBS yielded dissimilar elemental contents. EDS $\left(\mathrm{C}_{0.768} \mathrm{O}_{0.179} \mathrm{~S}_{0.053}\right)$ produced lower carbon and higher oxygen and sulfur contents than XPS $\left(\mathrm{C}_{0.861} \mathrm{O}_{0.112} \mathrm{~S}_{0.027}\right)$ and RBS $\left(\mathrm{C}_{0.845} \mathrm{O}_{0.124} \mathrm{~S}_{0.031}\right)$. Compared to the theoretical composition of polysulfone $\left(\mathrm{C}_{0.844} \mathrm{O}_{0.125} \mathrm{~S}_{0.031}\right)$ [23], the composition determined by RBS was very close, within $1 \%$ for all three elements. XPS also yielded concentrations that were similar to theoretical concentrations. By contrast, EDS yielded a markedly lower carbon concentration and markedly higher oxygen and sulfur concentrations than those in the theoretical composition of polysulfone and XPS and RBS results.

\subsubsection{Chemically depth-heterogeneous samples: TFC-S and TFC-ULP membranes}

We used unfouled TFC-S and TFC-ULP membranes as controls for the fouled membranes, and as surrogates for thick depth-heterogeneous foulant layers or thin foulant layers on NF/RO membranes. We use the qualifier 'thin' to refer to layers thinner than the analysis depth of the analytical technique used. The unfouled TFC-S and TFC-ULP membranes are well-defined samples in terms of chemical depth heterogeneity with polyamide active layers $\approx 100 \mathrm{~nm}$ thick [3] on polysulfone supports. The polyamide active layers are significantly thinner than the analysis depths of EDS and RBS, but thicker than the analysis depth of XPS. 
Table 2. Technical details, benefits, and drawbacks of EDS, XPS and RBS as analytical techniques for the characterization of elemental composition.

\begin{tabular}{|c|c|c|c|}
\hline Property & EDS $[48,49]$ & XPS $[48,50]$ & RBS [51] \\
\hline \multicolumn{4}{|c|}{ Experimental setup and sample information } \\
\hline Incident beam & Electrons & X-rays & Helium ions \\
\hline Emission beam & X-rays & Photo-electrons & Helium ions \\
\hline Sample preparation & Vacuum drying & Vacuum drying & Vacuum drying \\
\hline $\begin{array}{l}\text { Conductive coating } \\
\text { requirements }\end{array}$ & $\begin{array}{l}\text { Monoelement } \\
\text { coating of known } \\
\text { depth }\end{array}$ & No coating required & No coating required \\
\hline Analysis area (per sample) & Fractions of a $\mathrm{mm}^{2}$ & Fractions of a mm ${ }^{2}$ & Few to tens of $\mathrm{cm}^{2}$ \\
\hline Analysis time (per sample) & $\sim 5 \mathrm{~min}$ & $\begin{array}{c}\text { Survey: minutes } \\
\text { High-res: } \sim 1 \mathrm{~h}\end{array}$ & $\sim 35 \mathrm{~min}$ \\
\hline Analysis depth & Few microns & $<10 \mathrm{~nm}$ & $\sim 1-2 \mu \mathrm{m}$ \\
\hline \multicolumn{4}{|c|}{ Benefits and drawbacks } \\
\hline Instrument availability & Most common & Less common & Rare \\
\hline Analyst training required & Minimal & Significant & Very Significant \\
\hline $\begin{array}{c}\text { Able to depth profile } \\
\text { composition }\end{array}$ & No & Yes $^{a}$ & Yes \\
\hline $\begin{array}{c}\text { Able to visualize and } \\
\text { analyze specific target } \\
\text { features }\end{array}$ & Yes & No & No \\
\hline $\begin{array}{c}\text { Produces high-resolution } \\
\text { images }\end{array}$ & Yes & No & No \\
\hline $\begin{array}{c}\text { Effect of depth- } \\
\text { heterogeneous sample }\end{array}$ & $\begin{array}{l}\text { Software assumes } \\
\text { homogeneous } \\
\text { sample }\end{array}$ & $\begin{array}{c}\text { Sensitive to depth } \\
\text { heterogeneity on } \\
\text { length scales }<10 \\
\mathrm{~nm}\end{array}$ & $\begin{array}{l}\text { Nanometer-scale } \\
\text { depth resolution } \\
\text { allows for profiling } \\
\text { multiple strata, } \\
\text { including strata } \\
\text { thicknesses }\end{array}$ \\
\hline $\begin{array}{c}\text { Effect of surface roughness } \\
\text { on elemental composition } \\
\text { quantification }\end{array}$ & $\begin{array}{l}\text { Potentially } \\
\text { significant }\end{array}$ & Not significant & Not significant \\
\hline $\begin{array}{l}\text { Provides information about } \\
\text { bond type of element of } \\
\text { interest }\end{array}$ & No & Yes & No \\
\hline Ease of use & Easy & Moderate & Difficult \\
\hline
\end{tabular}

Notes: ${ }^{a}$ It is possible to obtain depth profiling information using angle-resolved XPS or removing sample from the surface by ion sputtering; however, both approaches substantially increase analysis time and ion sputtering causes sample damage [50,52]. 

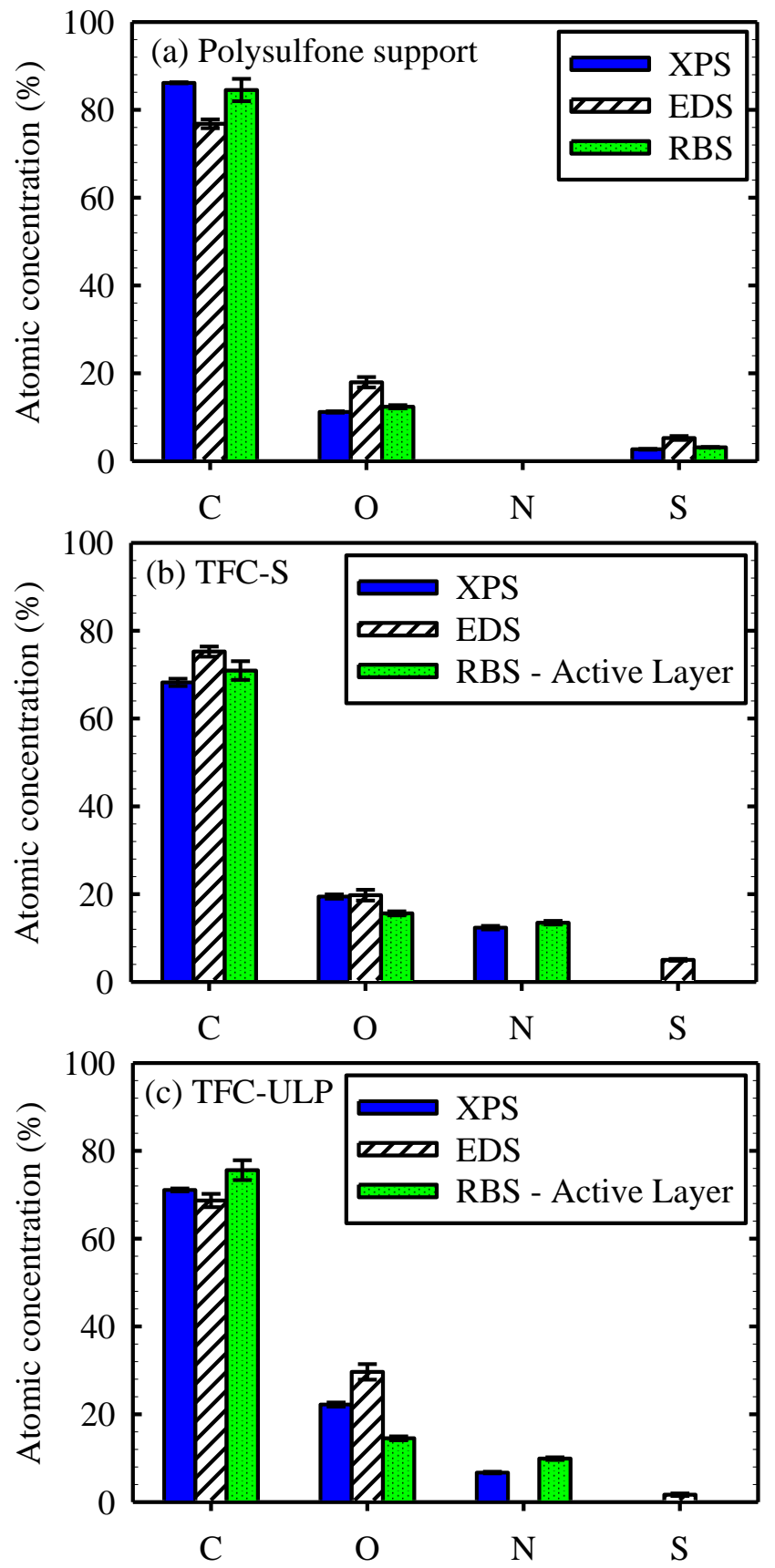

Figure 1. Elemental compositions of unfouled (a) polysulfone support, (b) TFC-S, and (c) TFCULP membrane samples obtained by EDS, XPS and RBS analyses. RBS results for TFC-S and TFC-ULP correspond to those obtained for their active layers. For both TFC-S and TFC-ULP membranes, the elemental composition of their support layers was the same as that of the polysulfone support in panel (a). The theoretical composition of polysulfone and fully crosslinked aromatic polyamide are $\mathrm{C}_{0.844} \mathrm{O}_{0.125} \mathrm{~S}_{0.031}[23]$ and $\mathrm{C}_{0.750} \mathrm{O}_{0.125} \mathrm{~N}_{0.125}[3,53]$, respectively. 
Elemental composition results for unfouled TFC-S and TFC-ULP membrane samples are shown in Figures 1b-1c. While EDS and XPS lack depth resolution and thus provide only one set of elemental composition values, RBS has nanometer scale depth resolution and is able to resolve the polyamide active layer from the polysulfone support, as described elsewhere [23]. Thus, in Figures $1 b-1 c$, we report the RBS results for the elemental compositions of the membrane active layers. The elemental composition of the polysulfone support was the same as in the unfouled polysulfone support without polyamide film analyzed in Figure $1 \mathrm{a}\left(\mathrm{C}_{0.845} \mathrm{O}_{0.124} \mathrm{~S}_{0.031}\right)$.

The results in Figure 1b-1c show that the elemental compositions obtained by XPS (TFC-S: $\mathrm{C}_{0.682} \mathrm{O}_{0.195} \mathrm{~N}_{0.123}$, TFC-ULP: $\left.\mathrm{C}_{0.711} \mathrm{O}_{0.222} \mathrm{~N}_{0.067}\right)$ and RBS (TFC-S: $\mathrm{C}_{0.709} \mathrm{O}_{0.156} \mathrm{~N}_{0.135}$, TFC-ULP: $\mathrm{C}_{0.756} \mathrm{O}_{0.145} \mathrm{~N}_{0.099)}$ were similar between the two techniques, and consistent with partially crosslinked aromatic polyamide with pendant carboxylic groups (i.e., the oxygen and nitrogen contents were higher and lower, respectively, than in fully crosslinked aromatic polyamide $\left.\left(\mathrm{C}_{0.750} \mathrm{O}_{0.125} \mathrm{~N}_{0.125}\right)[3,53]\right)$. By contrast, the compositions obtained by EDS (TFC-S: $\mathrm{C}_{0.752} \mathrm{O}_{0.198} \mathrm{~S}_{0.050}$, TFC-ULP: $\left.\mathrm{C}_{0.687} \mathrm{O}_{0.296} \mathrm{~S}_{0.017}\right)$ were markedly different from those obtained by XPS and RBS, and did not indicate the presence of nitrogen in the membrane, yielding elemental concentrations for the TFC-S membrane similar to those for the polysulfone support.

Figure 2 illustrates the ability to determine from visual inspection of RBS spectra the depth heterogeneity of the sample analyzed. The figure presents the RBS spectrum obtained for the unfouled TFC-ULP membrane superimposed to that of the unfouled polysulfone support. The plateau shape of elemental signals for the polysulfone sample is indicative of elements having a constant concentration in depth. The elemental signal of carbon is an exception to this behavior, typically rising up at lower energies [37]. For the TFC-ULP sample, the peak signal of nitrogen 
indicates that this element is present only at a certain depth range (in the polyamide active layer in this case), but is absent deeper in the sample (in the polysulfone support).

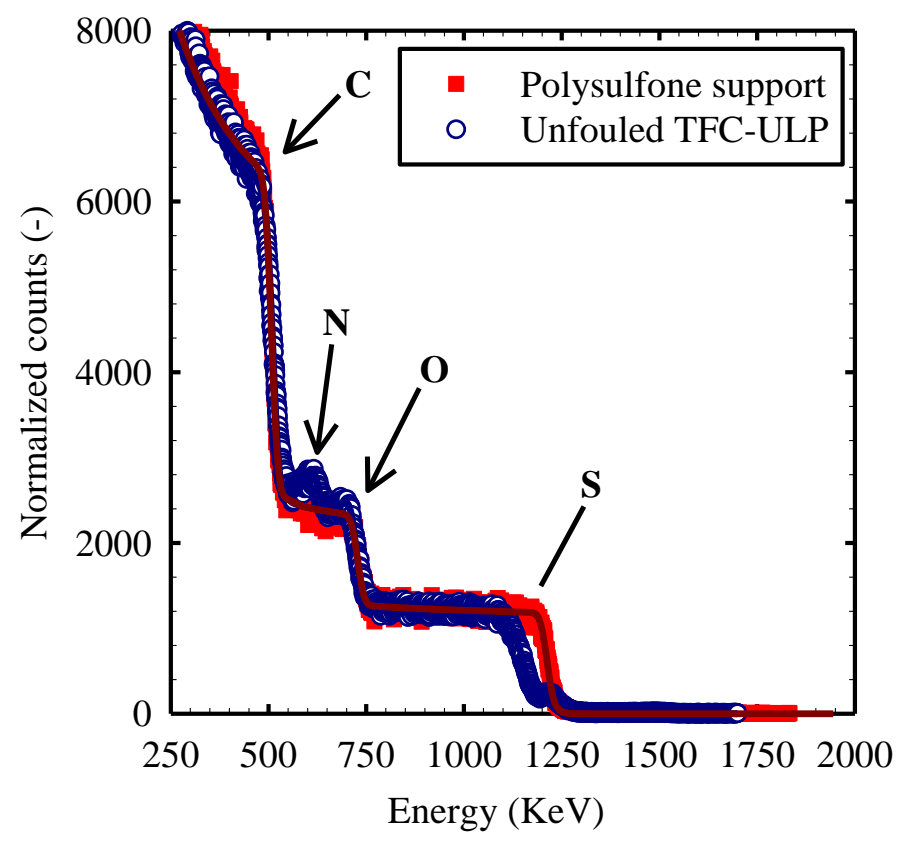

Figure 2. RBS spectrum of the unfouled TFC-ULP membrane $\left(\mathrm{C}_{0.756} \mathrm{O}_{0.145} \mathrm{~N}_{0.099}\right.$, red squares) superimposed to that of the (unfouled) polysulfone support $\left(\mathrm{C}_{0.845} \mathrm{O}_{0.124} \mathrm{~S}_{0.031}\right.$, empty circles). Symbols and lines correspond to data and simulation, respectively. The RBS spectrum for the unfouled TFC-S membrane (not shown) is indistinguishable from that of the TFC-ULP membrane [38].

\subsection{Membrane samples of unknown chemical composition}

\subsubsection{Visual and SEM assessment of foulant layers and chemical cleaning efficacy}

Figure 3 shows SEM micrographs of the four fouled membranes before and after chemical cleaning. Each image is representative of multiple samples collected from the corresponding spiral wound element. The images show that fouled membrane samples were completely covered by foulant layers with all foulant layers being morphologically different. CHS1, CHS2, and PDS1 membranes had relatively uniform foulant layers, while PDS2 had repeating crystalline foulants approximately $100 \mu \mathrm{m}$ in diameter surrounded by a uniform foulant layer. Given that 
membrane foulant layers covered the entire surface of the samples analyzed, these samples were good candidates to compare foulant layer compositions obtained by EDS, XPS, and RBS (i.e., the membrane surface was not a combination of foulant layer and membrane active layer).

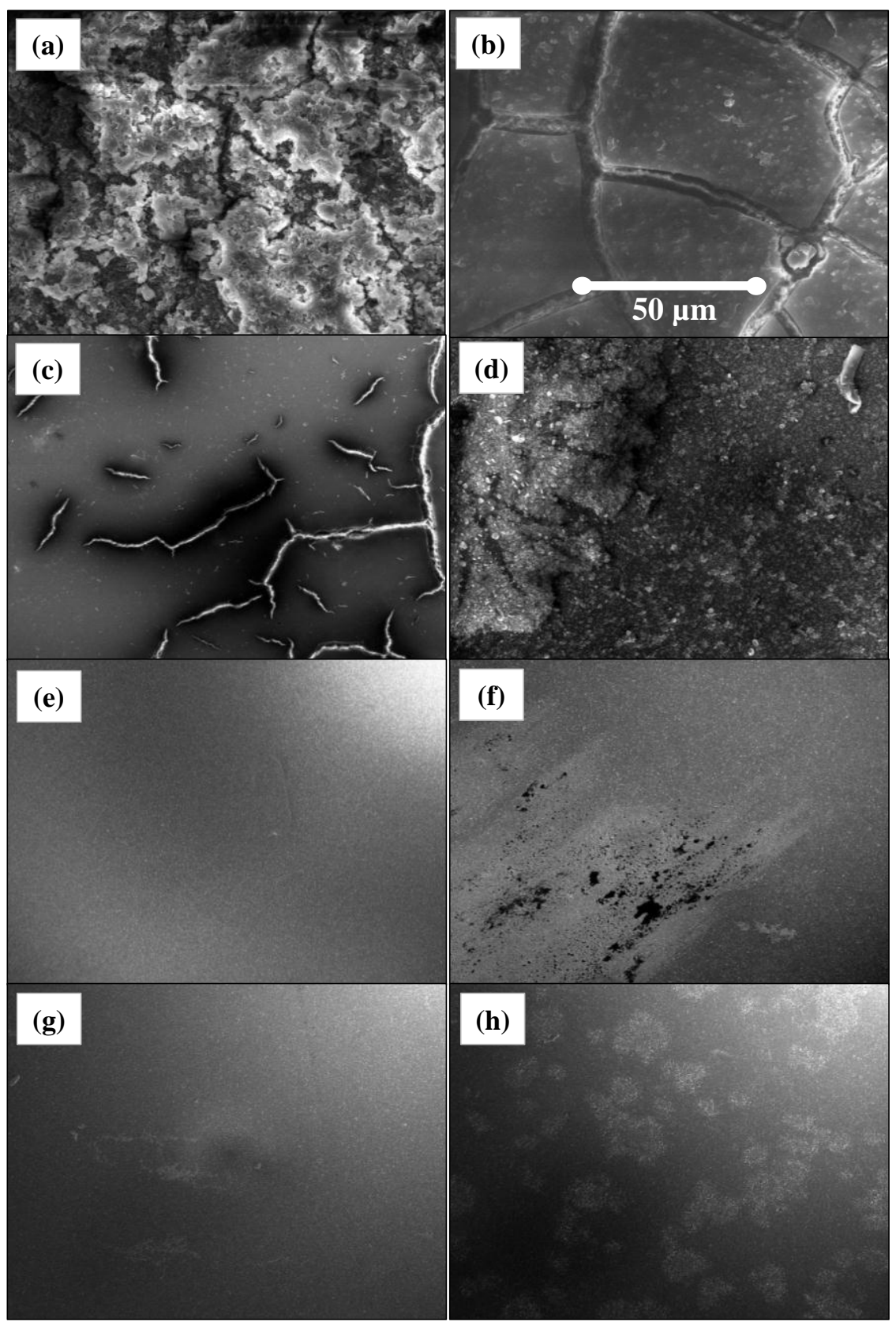

Figure 3. SEM micrographs of fouled membrane samples before (a-d) and after (e-h) cleaning with STPP+EDTA. Membrane samples were collected from the (a,e) CHS1, (b,f) CHS2, (c,g) PDS1, and $(d, h)$ PDS2 stages. Images in panels (a) and (b) have been reprinted from Gorzalski and Coronell [38], Copyright 2014, with permission from Elsevier. 
The SEM images in Figure 3 also show that chemical cleaning was effective at removing the foulant layers, with visible discoloration that may indicate residual trace foulants in CHS2 (Figure 3f) and PDS2 (Figure 3h) membranes. Since only the majority of foulants, but not all of them, were removed by chemical cleaning, then elemental composition analyses of cleaned membrane samples by EDS, XPS, and RBS characterized both the active layers and trace foulants on them.

The results obtained by SEM were consistent with visual observations. All fouled membrane samples had visible foulant layers in patterns that mirrored the feed spacers. CHS1 and CHS2 samples had an orange tinge consistent with iron content. PDS1 was white in color with black lines, and PDS2 had a rough, textured surface. Similarly, the effectiveness of chemical cleaning was visible by eye, with most foulants dissolving into cleaning solutions, and a portion of the PDS2 foulant layer appearing to remain after cleaning.

\subsubsection{Elemental composition and thickness of foulant layers}

Figure 4 shows the elemental composition results for fouled membrane samples. The panels on the left present the atomic concentrations of carbon, oxygen and nitrogen, which make up most of the elements present in organic foulants and the subjacent membrane. The panels on the right present the atomic concentrations of aluminum, silica, sulfur, calcium and iron, which are the elements present in inorganic foulants (although sulfur from the polysulfone support may also contribute to the signal detected by EDS). As seen in Figure 4, the three analytical techniques indicated that all four foulant layers had lower carbon and higher oxygen contents than unfouled membranes. The three techniques also detected aluminum, silicon, sulfur, calcium, and iron in each of the foulant layers, although in varying concentrations. Notably, EDS detected fewer 

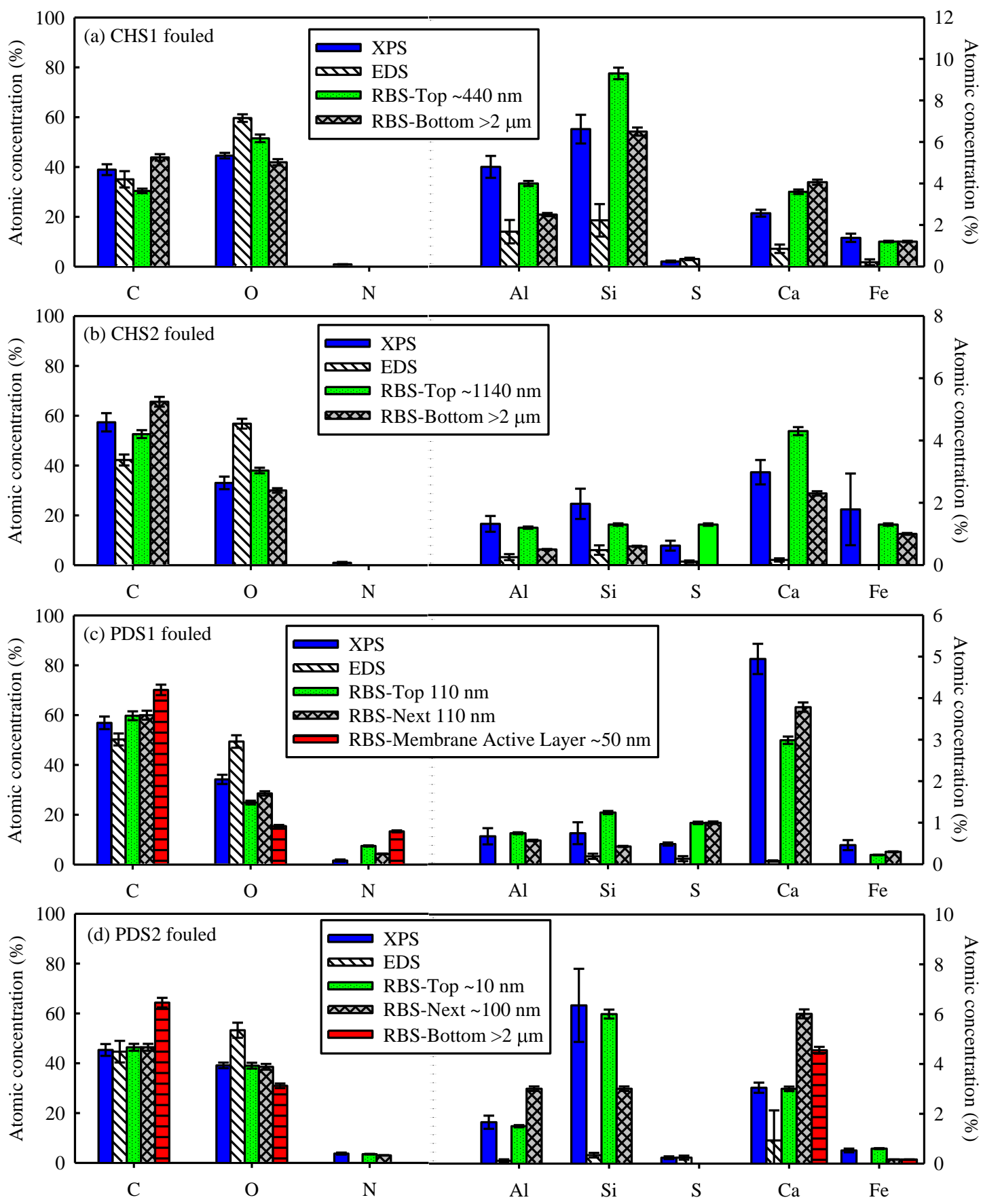

Figure 4. Elemental compositions of fouled (a) CHS1, (b) CHS2, and (c) PDS1, and (d) PDS2 membrane samples obtained by XPS, EDS, and RBS analyses. The left $y$-axis corresponds to the atomic concentration of $\mathrm{C}, \mathrm{O}$ and $\mathrm{N}$. The right $y$-axis corresponds to the atomic concentration of $\mathrm{Al}, \mathrm{Si}, \mathrm{S}, \mathrm{Ca}$ and $\mathrm{Fe}$. Error bars for EDS and XPS results indicate standard deviations for a minimum of three replicate samples. Error bars for RBS results indicate the error of the fitting $(\leq 3 \%)$. For the CHS1, CHS2, and PDS2 samples, the foulant layers were found to be thicker than the depth of analysis of RBS $(\approx 2 \mu \mathrm{m})$. For the PDS1 sample, the foulant layer was found to be thinner $(220 \mathrm{~nm})$ than the depth of analysis of RBS. 
elements than XPS and RBS. For example, while EDS did not detect nitrogen in any of the samples, XPS detected nitrogen in all samples, and RBS detected it in PDS1 and PDS2 samples. Also, while EDS did not detect iron in three (CHS2, PDS1 and PDS2) out of the four types of samples, XPS and RBS detected it in all samples. Similarly, EDS did not detect aluminum in PDS1 and PDS2 samples, but XPS and RBS did detect aluminum. Also, for all foulant layers, the total inorganic foulant signal was generally lower for EDS than for XPS and RBS, which was likely due to the greater analysis depth of EDS, yielding signal from the subjacent membrane.

The thicknesses of the foulant layers and their strata, obtained from RBS data analyses using SIMNRA 6.06v [46], are presented in Figure 4. We use the word "stratum" to refer to each of the distinctly different sublayers that can be thought to make up a depth-heterogeneous foulant layer (e.g., a top stratum with high concentration of iron, followed by a middle stratum with a low concentration of iron, followed by a bottom stratum with no iron). The concept of different strata, each with a different homogeneous elemental composition, is required because RBS simulations do not allow for the use of layers with changing composition as a function of depth. The thickness results show that while the foulant layers of the CHS1, CHS2, and PDS2 samples were thicker than the analysis depth of RBS $(\approx 2 \mu \mathrm{m})$, the foulant layer of the PDS1 samples was only 220 nm thick. All foulant layers were observed to be depth heterogeneous containing at least two strata identifiable by RBS. For each of the CHS1, CHS2, and PDS1 membranes, the different strata of the foulant layer contained approximately the same elements, though in different concentrations; however, for the PDS2 membrane, some elements present in the top $\sim 110 \mathrm{~nm}$ of the foulant layer (i.e., aluminum, silicon) were absent underneath that top region.

\subsubsection{Elemental composition of cleaned membrane samples}


Figure 5 shows the elemental compositions of fouled membrane samples following cleaning. The EDS results show that the measured carbon, nitrogen (not detected), and oxygen contents in cleaned samples (Figure 5) were similar to those measured in unfouled samples (Figures 1b-1c). The EDS results for cleaned samples also show a reduced, but non-zero, content of inorganic constituents (aluminum, silicon, sulfur, calcium, and iron) compared to in fouled samples, indicating that minor amounts of foulants remained on the membrane surfaces after cleaning.

The XPS results for cleaned membranes (Figure 5) indicate that the measured surface carbon, oxygen, and nitrogen contents were similar to those measured in unfouled membranes (Figures 1b-1c). Thus, XPS results indicate that most of the foulant layers were removed, and that only minor amounts of foulants remained on the membrane surfaces. The XPS results also indicate that inorganics are important components of the foulants remaining on the membrane surfaces after cleaning, as aluminum, silicon, sulfur, calcium and iron were detected in all cleaned samples, with aluminum and silicon being the elements detected at the highest concentrations (up to $\approx 4$ at $\%$ ).

The RBS results for cleaned samples (Figure 5) show that thin ( 40-53 nm) foulant layers remained after cleaning, and that these layers contained aluminum and silicon as main inorganic foulants, consistent with XPS results. RBS was able to detect the active layers of the subjacent membranes below these thin foulant layers, and the elemental compositions of these active layers (Figure 5) were found to be largely similar to those in the unfouled membranes (Figure 1b-1c).

Overall, the results in Figure 5 indicate that all three techniques detected lower contents of inorganic constituents in the fouled samples after cleaning compared to in the corresponding uncleaned fouled samples. The three techniques were also consistent in detecting lower 

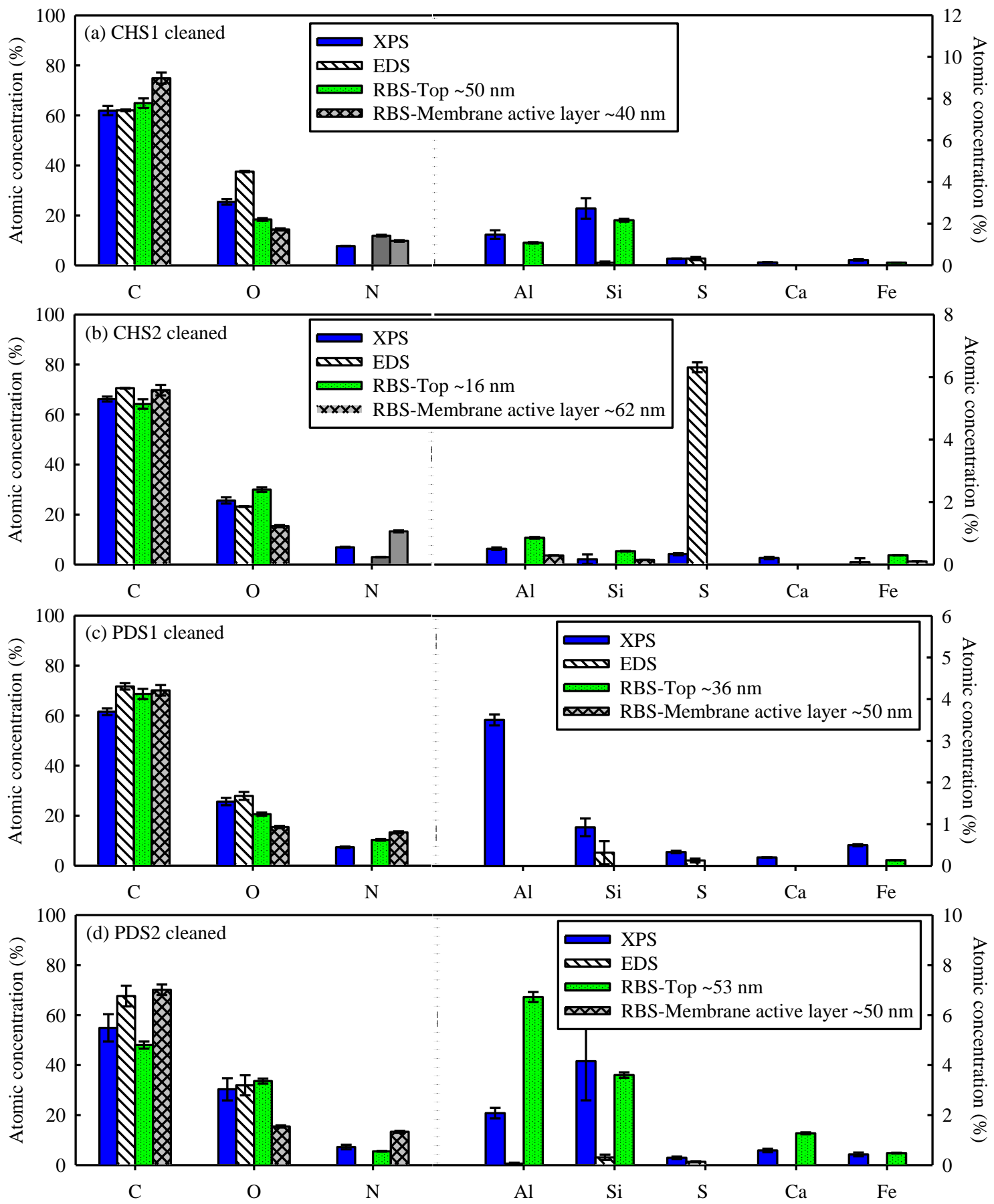

Figure 5. Elemental compositions of fouled (a) CHS1, (b) CHS2, (C) PDS1, and (D) PDS2 membrane samples following cleaning with STPP+EDTA obtained by XPS, EDS, and RBS. The left $y$-axis corresponds to the atomic concentration of $\mathrm{C}, \mathrm{O}$ and $\mathrm{N}$. The right $y$-axis corresponds to the atomic concentration of $\mathrm{Al}, \mathrm{Si}, \mathrm{S}, \mathrm{Ca}$ and $\mathrm{Fe}$. Error bars for EDS and XPS results indicate standard deviations for a minimum of three replicate samples. Error bars for RBS results indicate the error of the fitting $(\leq 3 \%)$. For all samples, the remaining foulant layers on the membrane surfaces were found to be thinner than the depth of analysis of RBS $(\approx 2 \mu \mathrm{m})$. 
reductions of aluminum and silicon content with cleaning, compared to corresponding reductions of calcium and iron content. XPS and RBS were more sensitive than EDS to trace foulants that remained on the membrane surface after cleaning. Finally, RBS was able to discriminate the elements present in the remaining foulant layers from those present in the active layer.

\section{Discussion}

In this section we discuss our experimental results towards assessing the efficacy of each of the three techniques (XPS, EDS and RBS) in the analysis of membranes and their foulant layers in relation to the following specific applications: detection of major elements in thick layers, detection of major elements in thin layers, evaluation of overall membrane cleaning efficacy, detection of trace foulants, detection of major elements in depth-heterogeneous samples, characterization of sample depth heterogeneity, determination of thickness of foulant and active layers, visual observation of surface features, and distinction of foulants from membrane by bonding signature. The outcomes of our assessments are summarized in Table 3.

\subsection{Method suitability for elemental analyses of membrane samples on the basis of results for samples with known chemical composition}

The analyses of membranes of known theoretical composition (i.e., polysulfone support and TFC-ULP and TFC-S membranes) enabled us to draw conclusions about method suitability for membrane analyses. For polysulfone support samples, XPS and RBS results were closer than EDS results to the theoretical composition of polysulfone (Figure 1a), and thus we conclude that XPS and RBS are more accurate than EDS for analysis of membrane samples that are chemically homogeneous with depth. The apparent underestimation of carbon content, and overestimation of 
oxygen and sulfur contents, by EDS likely resulted from invalid assumptions that the EDS

software uses in the calculation of elemental concentration. These software assumptions are not likely to be unique to the specific software used and are discussed in more detail in Section 4.3.

Table 3. Efficacy of EDS, XPS, and RBS in different applications specific to the analysis of membranes and their foulant layers, as investigated in the present study.

\begin{tabular}{cccc}
\hline \multicolumn{1}{c}{ Application } & EDS & XPS & RBS \\
\hline $\begin{array}{c}\text { Detection of major elements in } \\
\text { thick surface layers a,b }\end{array}$ & Effective & Effective & Effective \\
\hline $\begin{array}{c}\text { Detection of major elements in } \\
\text { thin surface layers a,c }\end{array}$ & Not effective & Effective & Effective \\
\hline $\begin{array}{c}\text { Assessment of overall cleaning } \\
\text { efficy }\end{array}$ & Effective & Not effective & Effective \\
\hline $\begin{array}{c}\text { Detection of trace foulants } \\
\text { depth-heterogeneous samples } \\
\begin{array}{c}\text { Characterization of sample } \\
\text { chemical depth heterogeneity }\end{array}\end{array}$ & Not effective & Effective & Effective \\
\hline $\begin{array}{c}\text { Determination of thickness of } \\
\text { foulant and active layers }\end{array}$ & Not applicable & Not effective & Effective \\
\hline $\begin{array}{c}\text { Visual observation of surface } \\
\text { features, fouling, cleaning }\end{array}$ & Effective & Not applicable & Effective \\
\hline $\begin{array}{c}\text { Distinction of foulants from } \\
\text { membrane by bonding signature }\end{array}$ & Not applicable & Effective & Not applicable \\
\hline
\end{tabular}

Notes: ${ }^{\text {a }}$ Thick and thin surface layers refer to layers that are thicker or thinner, respectively, than the analysis depth of the technique used, and that correspond to the top layer in the sample. ${ }^{\mathrm{b}}$ For example, a polysulfone support or a foulant layer thicker than the analysis depth of the technique used. ${ }^{c}$ For example, a polyamide active layer or a foulant layer thinner than the depth of analysis of the technique used.

For unfouled TFC-ULP and TFC-S membranes, XPS and RBS produced active layer elemental compositions that were consistent with fully crosslinked aromatic polyamide (Figures 1b-1c). The minor discrepancies observed between XPS and RBS results may have been the product of the different analysis areas of the techniques (i.e., four orders of magnitude larger for RBS than for XPS), or actual differences between surface (XPS) and volume-averaged (RBS) compositions 
of the active layers, as reported elsewhere [14]. Contrary to XPS and RBS, EDS did not detect nitrogen in the unfouled thin-film composite samples, which indicates that EDS had limited sensitivity to the top polyamide active layer. The lack of nitrogen detection is in part due to the analysis depth of EDS. Specifically, given that only the active layer contains nitrogen, and the active layer is relatively thin $(\sim 100 \mathrm{~nm})$ compared to the analysis depth of EDS (a few microns), most of the signal is generated by the polysulfone support, not by the polyamide active layer.

Thus, it can be concluded that the three techniques are effective at detecting major elements in thick surface layers, but only XPS and RBS are effective at detecting major elements in thin surface layers. By extension, from EDS results alone, it would be difficult to infer the presence of a thin surface layer on a depth-heterogeneous sample, such as the active layer of a thin-film composite membrane, or a thin foulant layer on a membrane.

\subsection{Method suitability for elemental analyses of foulant layers and assessment of membrane cleaning}

\subsubsection{Analyzing elemental composition of membrane foulant layers}

Despite the different results obtained among the three analytical techniques for polysulfone support samples, the variability among the results or their deviation from the theoretical composition of polysulfone is likely not of concern when analyzing thick foulant layers. For the elemental analysis of foulant layers, one is typically interested in whether or not a given element is present and the order of magnitude in which it is present, not the exact concentrations of the elements in the sample. For example, EDS was able to detect most elements present in the thick foulant layers of the fouled CHS1, CHS2 and PDS2 membrane samples (Figure 4). Therefore, 
we conclude that any technique among EDS, XPS or RBS can likely be used for the identification of specific elements and estimation of the relative magnitude of their concentration in thick foulant layers, provided that the elements are above detection limit.

By contrast, EDS did not detect all the constituents that XPS and RBS detected in thin foulant layers (Figure 4c), and did not detect nitrogen in TFC-S and TFC-ULP samples, which were surrogates for thin foulant layers (Figures 1b-1c). Potential explanations include detection limits and sample depth heterogeneity. EDS and XPS have similar limits of detection from approximately 0.1 atomic percent (at $\%$ ) for heavier elements to a few atomic percent for lighter elements such as nitrogen [24,50], and RBS has detection limits on the order of 0.01 at $\%$ for heavy elements and a fraction of an atomic percent for light elements [37,54-56]. This would explain why some elements were detected by RBS and not EDS, but not why they were detected by XPS and not EDS. Depth heterogeneity may have played a role in the latter. As EDS probes a few microns from the sample surface, if an element is present in only a fraction of the depth analyzed, even at a concentration above the EDS detection limit, the signal from that element will be 'diluted' due to its absence in the rest of the depth probed, and thus may not be detected. This is not a likely problem to occur for XPS because XPS probes a very limited region from the sample surface $(\leq 10 \mathrm{~nm})$, or for RBS which has a depth resolution on the order of several nanometers. Therefore, we conclude that thin foulant layers are best characterized using XPS or RBS, and that EDS is not well suited to the analysis of thin foulant layers.

\subsubsection{Assessing membrane cleaning and presence of remaining trace foulants}

EDS, XPS, and RBS performed differently in the analysis of cleaned membrane samples with EDS detecting fewer elements than XPS and RBS (Figure 5). The reasons for the lack of 
detection of some elements by EDS are the same as discussed in the previous section. Therefore, while XPS and EDS are effective at detecting trace foulants, EDS is not. However, given that the elemental contents of the major elements (carbon, oxygen) detected by EDS in cleaned samples (Figure 5) were similar to those in unfouled samples (Figures 1b-1c), we conclude that EDS is effective at evaluating overall cleaning efficacy.

XPS results showed that the nitrogen content in cleaned membrane samples (Figure 5) was similar to that in unfouled NF membranes (Figures 1b-1c), which indicates that a large fraction of the XPS signal originated in the membrane active layer, and that the foulants remaining on the membrane surfaces were not present in the form of distinct foulant layers. Rather, the remaining foulants were distributed across the membrane surface in a non-uniform manner, as illustrated by the SEM images in Figures 3f-3h. The remaining foulants may fill the valleys of the ridge-andvalley surface morphology [3] of the active layers, which are known to be several tens and up to over a hundred nanometers deep $[3,14,57,58]$. We note that while XPS was able to detect substantial removal of the foulant layers by chemical cleaning, this would not have been possible if the residual foulants covered a large fraction of the membrane surface with a uniform thickness of more than $\sim 10 \mathrm{~nm}$ (i.e., if no signal were generated at the active layer despite substantial removal of foulants). Thus, we conclude that XPS is effective at detecting trace foulants, but is not an appropriate technique to evaluate overall cleaning efficacy.

RBS results for cleaned membrane samples were in general consistent with XPS results (Figure 5), with the exception that RBS did not have enough sensitivity to detect the presence of some trace elements at the membrane surfaces, in particular for the PDS1 membrane (Figure 5c). This observation could potentially be explained by spatial heterogeneity of the membrane sample 
resulting in different outcomes for XPS and RBS analyses, or the lower sensitivity of RBS to elements with a lower atomic mass. The elemental sensitivity of RBS increases with the square of the atomic number [37], meaning that RBS is approximately four times as sensitive to iron (a heavier element which was detected) as it is to aluminum and silicon (lighter elements which were not detected). RBS, however, was the only technique with the capability of estimating the average thicknesses of the trace foulant layers remaining after cleaning (Figure 5). The fact that the obtained foulant layer thicknesses $(<50 \mathrm{~nm})$ were similar or smaller than the typical scale of surface roughness for polyamide membrane surfaces (i.e., tens to over a hundred nanometers $[3,14,57,58])$ is consistent with our observation that the trace foulants were distributed across the membrane surface in a non-uniform manner and filled the valleys of the ridge-and-valley surface morphology of the membranes. When the thicknesses of the remaining foulant layers after cleaning are compared with the thicknesses of the original foulant layers (>220 nm for PDS1, >2 $\mu \mathrm{m}$ for all others, Figure 4), it can be concluded that the cleaning procedure was generally effective. Thus, we conclude that RBS is effective at evaluating overall cleaning efficiency.

\subsection{Sources of inaccuracies of elemental analysis of membrane samples by EDS}

As discussed in Section 4.2, detection limits and sample depth heterogeneity played a role in the inaccuracies in elemental compositions obtained from EDS analyses for fouled and cleaned samples. An additional factor contributing to the inaccuracies observed not only for fouled and cleaned samples, but also for unfouled samples, was the limitations of EDS software to precisely account for electron and X-ray interactions within the sample, a phenomenon that would need to be accurately known to obtain accurate elemental compositions [24,59-61]. EDS data analysis (performed through commercial software packages) takes into account factors such as the density 
of the material analyzed and the accelerating voltage of the electrons, and makes assumptions about the material properties (e.g., X-ray absorption and X-ray fluorescence are similar to preloaded standards) and sample properties (e.g., samples are flat-polished, conductive, and homogeneous), to calculate the electron interaction volume [24,59-61]. As several of the assumptions are typically not valid for membrane samples, it is almost impossible for the EDS software to precisely model the membranes analyzed [24,59-61].

As seen in Figure 6, a negative atomic concentration resulted when the EDS software was forced to account for the presence of nitrogen in the active layer of an unfouled thin-film composite sample. The exact reasons why this occurs is beyond the scope of this study, but it is related to the fact that forcing the software to calculate for nitrogen is equivalent to forcing the software to assume an erroneous structure and composition of the sample [24]. Specifically, as EDS does not have depth resolution, the software assumes that nitrogen is present throughout the whole depth of analysis, which is incorrect because it is present only in about $5 \%$ or less of the depth probed (i.e., in the polyamide active layer). The lack of detection or inaccurate quantification of nitrogen in unfouled NF membranes indicates that similar lack of detection or inaccurate quantification of foulant elements will occur in fouled samples when the foulant layer has multiple layers (Figure 4), or the foulant layer thickness is smaller than the analysis depth (Figure 5).

Additional factors that limit the accuracy of elemental analysis by EDS [60] are provided in the Supplementary Material. Specifically, we discuss (i) the qualitative misidentification of minor and trace constituents by the software, (ii) errors arising from the use of "standardless" analyses, and (iii) influence of geometric factors such as surface roughness that influence the generation and attenuation of X-rays. 


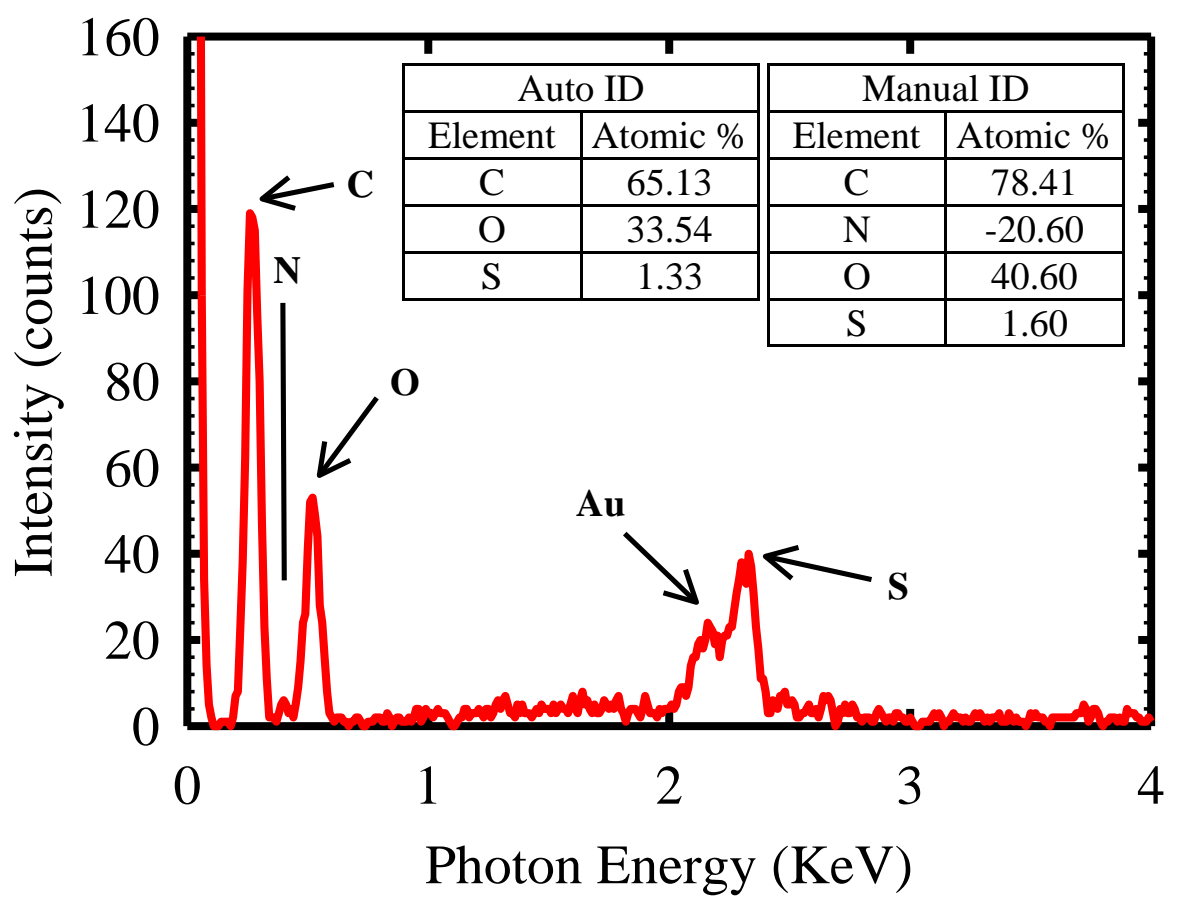

Figure 6. Nitrogen quantification using EDS in an unfouled TFC-ULP membrane. "Auto ID" refers to the mode of the EDS analysis software that uses the auto-identification feature to identify automatically the elements present in the sample. "Manual ID" refers to the mode in which the user manually identifies the elements. In the case of the spectrum presented in this figure, we manually indicated that carbon, nitrogen, oxygen, and sulfur were present in a sample coated with gold.

\subsection{Analysis of sample depth heterogeneity and foulant layer thickness}

EDS and XPS do not possess depth resolution, and therefore are not intended to determine sample depth heterogeneity or foulant layer thicknesses. For example, EDS results showed that carbon and oxygen were important components of the foulant layers (Figure 4). However, given that carbon and oxygen are also important constituents of the subjacent membranes (Figure 1), one cannot conclude whether the carbon and oxygen signals originated only from the foulant layers, which would indicate foulant layers thicker than the analysis depth of EDS, or from both the foulant layers and the subjacent membranes. XPS results do not help in assessing foulant layer thickness because XPS probes only the top $\approx 10 \mathrm{~nm}$ from the surfaces of the foulant layers. 
However, XPS can be used to determine if foulant layers were thicker than $10 \mathrm{~nm}$ (e.g., the significantly different compositions obtained by XPS for unfouled (Figure 1) and fouled (Figure 4) membrane samples indicates foulant layer thicknesses greater than $10 \mathrm{~nm}$ ). XPS could have been employed for depth profiling using either of two approaches: (i) collecting data with the sample tilted at different angles (i.e., angle-resolved XPS) which provides depth profiling information within the top $\sim 10 \mathrm{~nm}$ of a sample, or (ii) alternating XPS analysis and sample removal from the surface by ion sputtering which allows for profiling sample composition to greater depths $[50,52]$. Both approaches, however, would have substantially increased analysis time. Additionally, the ion sputtering beam would have caused substantial sample damage.

Unlike EDS and XPS, RBS was successful in discriminating different layers in the samples analyzed, including active layers from support layers (Figures 1b-1c), foulant layers from active layers (Figures 4 and 5), and different strata in foulant layers (Figure 4). This enabled the characterization of depth heterogeneity in elemental composition, and quantification of the thicknesses of the various layers present in the samples (up to the RBS analysis depth). While characterizing quantitatively the depth heterogeneity of the foulant layers requires analyzing the RBS data using a software package $[37,46]$, visual inspection of the raw RBS spectra allows for evaluation of whether the sample analyzed is depth heterogeneous as well as whether foulant layers are thinner or thicker than the analysis depth of RBS $(\sim 2 \mu \mathrm{m})$. For example, Figure 7 shows RBS spectra for representative thick (CHS1) and thin (PDS1) foulant layers superimposed to spectra for a corresponding unfouled membrane. The CHS1 spectrum bears little resemblance to the subjacent TFC-ULP membrane, with a much lower carbon signal, no nitrogen signal, and no sulfur plateau. The little resemblance to the unfouled membrane indicates that a negligible 

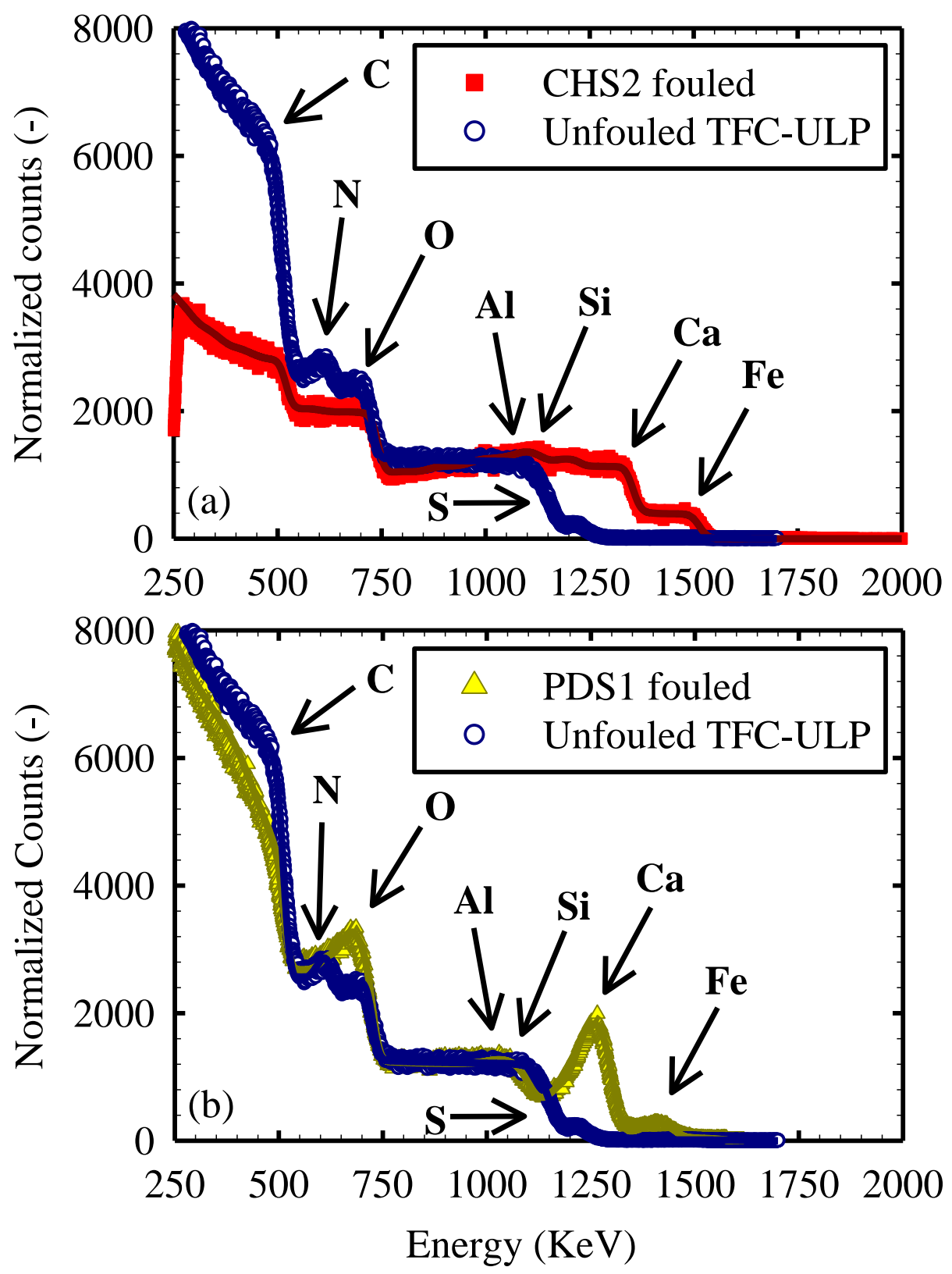

Figure 7. RBS spectra of samples of the fouled (a) CHS2 (red squares) and (b) PDS1 (yellow triangles) membranes, each of them superimposed to the spectrum of unfouled TFC-ULP membrane $\left(\mathrm{C}_{0.756} \mathrm{O}_{0.145} \mathrm{~N}_{0.099}\right.$, empty circles). Symbols and lines correspond to data and simulation, respectively. The RBS spectrum for the unfouled TFC-S membrane (not shown) is indistinguishable from that of the TFC-ULP membrane [38]. The foulant layers of the CHS2 and PDS1 samples were found to be thicker and thinner, respectively, than the depth of analysis of RBS, and their elemental compositions are provided in Figure 4. 
portion of the signal comes from the subjacent membrane and thus the foulant layer thickness is similar to or thicker than the RBS analysis depth. By contrast, the PDS1 spectrum was largely similar to an unfouled membrane with the primary elements of the foulant layer (oxygen and calcium) appearing as distinct peaks compared to the unfouled membrane. While the differences from the unfouled membrane indicate the presence of a foulant layer, the high resemblance to the unfouled membrane indicates that the foulant layer thickness is smaller than the RBS analysis depth. A similar qualitative analysis based on visual inspection of RBS spectra was performed to evaluate the presence and relative thickness of the polyamide active layer on the polysulfone support (Section 3.1, Figure 2), and the presence and relative thickness of a trace foulant layer remaining after cleaning (see Supplementary Material).

\subsection{Additional capabilities and limitations of EDS, XPS, and RBS}

\subsection{1. $E D S$}

An additional capability of EDS analysis, over XPS and RBS analyses, is that given that EDS is usually coupled with SEM, it can deliver high resolution images for visual inspection of fouling and cleaning (Figure 3). The visual nature of SEM-EDS also enables selecting specific foulant features, or regions of interest in the SEM image, for quantitative elemental analysis with EDS. For example, Figure 8a shows an SEM image of the surface of a fouled PDS2 membrane sample, and Figure $8 \mathrm{~b}$ shows the EDS spectra for a scale feature on the fouled membrane surface (Region\#1) and a fouled region without a visible scale feature (Region\#2). The EDS results indicate that Region\#1 has half as much carbon, twice as much oxygen, and significantly more calcium (34:1) than Region\#2, potentially indicating calcium carbonate fouling. 

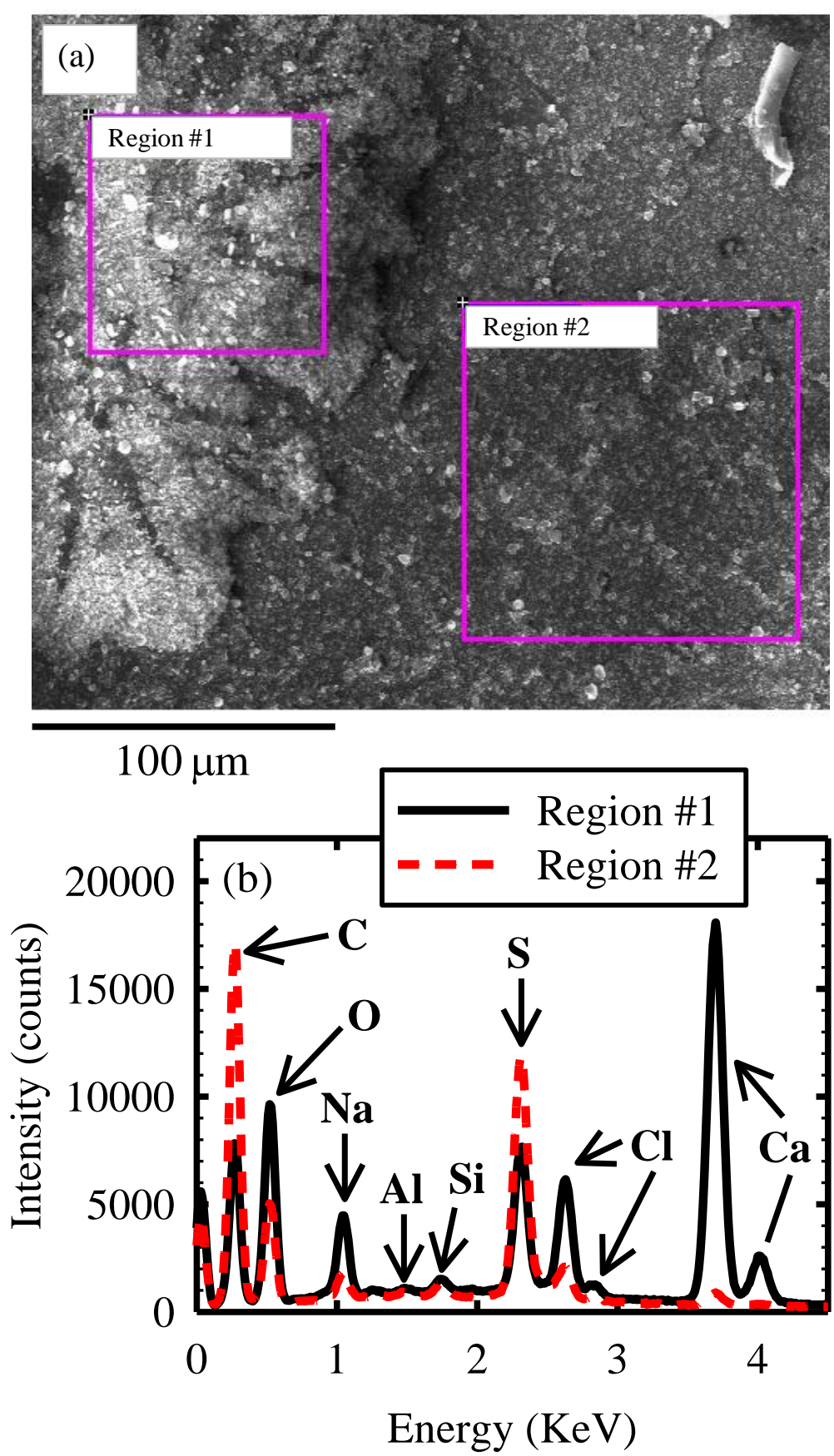

Figure 8. (a) SEM image and (b) EDS spectra for two regions on the surface of the fouled PDS2 membrane. Region\#1 corresponds to a scale feature on the fouled membrane surface, and Region\#2 corresponds to a fouled region without a visible scale feature. Given that specific features were analyzed in this sample, the analysis areas were specific to the region analyzed and different from the $300 \mu \mathrm{m} \times 400 \mu \mathrm{m}$ area analyzed for all other EDS samples in this study. The EDS results indicate the following ratios of elemental content in Region\#1 to elemental content in Region\#2: carbon $1: 2$, oxygen $2: 1$, sodium $4: 1$, sulfur $3: 4$, chlorine $4: 1$, and calcium $34: 1$. 
The limitations in the accuracy of EDS elemental analyses of complex samples discussed in Section 4.3 are compounded by the common practice of coating membrane samples with a layer of gold-palladium alloy prior to SEM imaging to prevent surface charging and provide better quality imaging [12,62-64]. Predicting X-ray adsorption in multi-element coatings presents substantial challenges [24], particularly when considering that the coating density and elemental deposition ratios may vary significantly from those of the native alloy. Thus, given that X-ray absorption can be predicted in single-element coatings (e.g., gold [65-67] as in this study, carbon/graphite [12,68,69], platinum [70]), and the properties (e.g., composition, density, thickness) of single-element coatings are more accurately known, single-element coatings are used for more accurate elemental quantification by EDS.

\subsubsection{XPS}

One distinct advantage of XPS over EDS and RBS is the ability to use differences in binding energy of core photoelectrons to discern the bonding condition of the element of interest. Past studies have used binding energy information from XPS analyses to examine differences in unfouled membranes [34-36] as well as in foulant layers [33,38], and to study membrane surface modifications aimed at minimizing membrane fouling [17,34,71-73]. Figure 9 is an illustrative example that compares the high-resolution XPS scans for the carbon 1s peak of the TFC-ULP and TFC-S membranes. Although the two membranes had comparable carbon concentrations (71 and $68 \%$ for the TFC-ULP and TFC-S membranes, respectively), the bonding condition of carbon in the membranes varied significantly. Compared to the TFC-S membrane, the TFC-ULP membrane had more carbon with a binding energy centered at $285.9 \mathrm{eV}$ which indicates $\mathrm{C}-\mathrm{O}, \mathrm{C}$ $\mathrm{N}$, or $\mathrm{C}-\mathrm{Cl}$ bonds, and less carbon with a binding energy centered at $287.9 \mathrm{eV}$ which indicates 

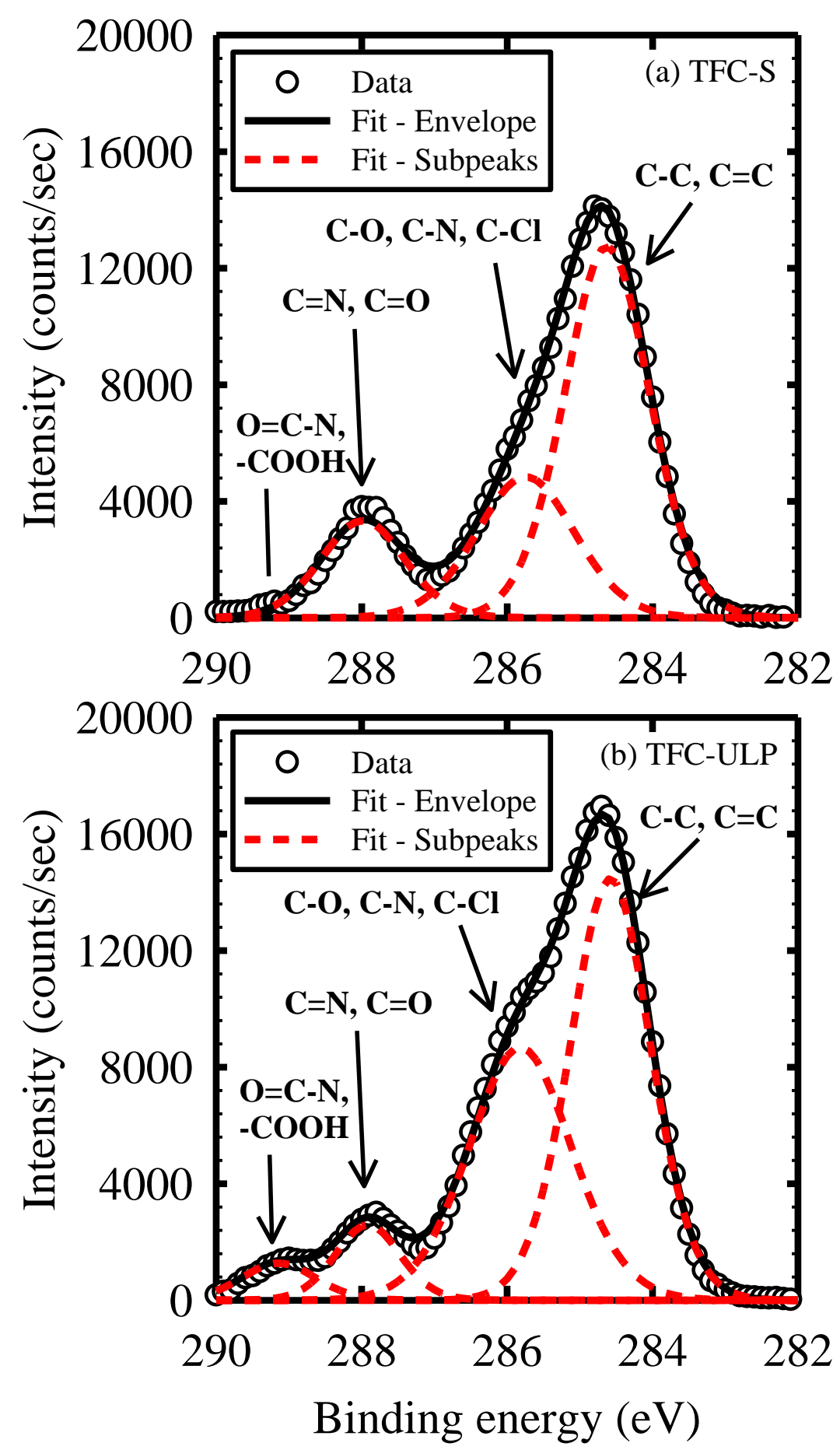

Figure 9. Comparison of high-resolution XPS scans for carbon 1s peaks for the (a) TFC-S and (b) TFC-ULP membranes. Symbols represent experimental data, continuous lines represent overall simulation lines, and dashed lines represent component peaks of the overall simulation lines. The spectra shown are representative examples of four and three replicate spectra obtained for the TFC-S and TFC-ULP membranes, respectively. 
$\mathrm{C}=\mathrm{O}$, or $\mathrm{C}=\mathrm{N}$ bonds $[13,35,36]$. The TFC-ULP membrane also had a visible peak centered at $289.1 \mathrm{eV}$, which was substantially less intense for the TFC-S membrane, and which indicates $\mathrm{COOH}$, or $\mathrm{O}=\mathrm{C}-\mathrm{N}$ groups. In addition, XPS can easily distinguish between different forms of sulfur $\left(\mathrm{C}-\mathrm{S}\right.$ vs $\left.\mathrm{SO}_{\mathrm{x}}\right)$ and nitrogen $\left(\mathrm{C}-\mathrm{NH}_{2} \mathrm{vs}_{\mathrm{NO}}\right)$ for example.

\subsection{3. $R B S$}

In addition to the depth-profiling capabilities of RBS, another unique advantage it holds over XPS and EDS is that the analysis area for RBS is orders of magnitude larger than that for EDS and XPS. For example, in this study the analysis areas for RBS, XPS and EDS were 2,000 $\mathrm{mm}^{2}$, $0.21 \mathrm{~mm}^{2}$ and $0.12 \mathrm{~mm}^{2}$, which are typical analysis areas for the three techniques [51]. Because of the significantly larger RBS analysis areas, RBS characterization results are more representative of the membranes analyzed than EDS or XPS results.

The most significant limitations of RBS are its complexity and lack of accessibility. Operation of RBS instrumentation, including the (tandem) accelerator needed to produce the analysis beam, is complex and requires significant training. Also, RBS provides only elemental composition information, but not visualization advantages like SEM-EDS (Figure 2) or information about

elemental bonding condition like XPS (Figure 9). Also, while the relatively large analysis area of RBS makes its results representative of a large membrane surface, it does not allow for the identification of small-scale (i.e., millimeter, micrometer) spatial heterogeneity in foulant layers, such as that described for the PDS2 foulant layer in Section 4.5.1 (Figure 8).

\section{Conclusions}


This is the first study to compare the suitability of EDS, XPS, and RBS for the qualitative and quantitative characterization of the elemental composition of thin-film composite membranes and their foulant layers. Table 3 summarizes our conclusions on the efficacy of each of the three techniques for nine specific applications discussed in this study related to membrane and foulant layer characterization. Our analysis also supports the following conclusions:

- Overall, RBS is the most advantageous technique for elemental analysis of membranes and foulant layers, as it is capable of characterizing elemental depth heterogeneity, including elemental composition and thickness of the different layers that comprise the sample analyzed (up to the RBS analysis depth). EDS is appropriate for quantifying major elements in thick foulant layers and determining overall cleaning efficacy. XPS is better suited to detect trace elements in membranes and foulant layer surfaces and small amounts of foulants remaining on cleaned membranes.

- This work provides numerous instances where the application of a single technique (EDS, XPS, or RBS) for elemental analyses may yield only partial information or even lead to an incorrect conclusion. This highlights the importance of selecting a suitable analysis technique for the experimental objectives, and understanding the strengths and limitations of each technique as discussed herein.

- EDS has the most limitations for the analysis of membranes and foulant layers, including inability to detect trace foulants, and inability to detect major foulants in thin membrane or foulant layers.

- XPS is not well-suited to detecting major elements in depth heterogeneous samples, nor to assess overall cleaning efficacy. 
- RBS does not have as high a sensitivity for trace foulants in the surfaces of membranes or foulant layers as XPS does. Also, RBS is a relatively complex technique that requires specialty instrumentation not commonly available.

\section{Acknowledgments}

This work was partially supported by the Water Resources Research Institute (WRRI) of the University of North Carolina and the US Geological Survey (WRRI project 11-03-W). The US Department of Defense supported Alexander S. Gorzalski through the Science, Mathematics and Research for Transformation (SMART) Scholarship for Service Program. RBS analyses were carried out at the Triangle Universities Nuclear Laboratories (TUNL), Durham, NC, which is partially supported by the US Department of Energy Office of Nuclear Physics Grant Numbers 97ER41041 and 97ER41033. XPS and SEM analyses were performed at the Chapel Hill Analytical and Nanofabrication Laboratory (CHANL) at the University of North Carolina at Chapel Hill. We thank Eliot Meyer, Joshua Powell, Lin Lin, John Dunham and Dr. Thomas Clegg for assistance in RBS analyses, and Dr. Amar Kumbhar for SEM-EDS analyses. We also thank our collaborators at the CFPUA, John Malone, Anthony Colon and Michael Richardson who helped and/or facilitated membrane and water sample collection, and Koch Membrane Systems and Hydranautics for donating membrane materials.

\section{Appendix A: Supplementary Material}

General approach used to analyze RBS data to obtain depth profile information. Additional factors that may affect the accuracy of EDS for elemental analysis. Assessment from RBS spectra of whether foulants remain on membrane surface after cleaning. 


\section{References}

[1] N. Hilal, H. Al-Zoubi, N. A. Darwish, A.W. Mohamma, M. Abu Arabi, A comprehensive review of nanofiltration membranes: Treatment, pretreatment, modelling, and atomic force microscopy, Desalination. 170 (2004) 281-308. doi:10.1016/j.desal.2004.01.007.

[2] L. Malaeb, G.M. Ayoub, Reverse osmosis technology for water treatment: State of the art review, Desalination. 267 (2011) 1-8. doi:10.1016/j.desal.2010.09.001.

[3] R.J. Petersen, Composite reverse osmosis and nanofiltration membranes, J. Membr. Sci. 83 (1993) 81-150. doi:10.1016/0376-7388(93)80014-O.

[4] K.P. Lee, T.C. Arnot, D. Mattia, A review of reverse osmosis membrane materials for desalination - Development to date and future potential, J. Membr. Sci. 370 (2011) 1-22. doi:10.1016/j.memsci.2010.12.036.

[5] A. Al-Amoudi, R. Lovitt, Fouling strategies and the cleaning system of NF membranes and factors affecting cleaning efficiency, J. Membr. Sci. 303 (2007) 4-28. doi:10.1016/j.memsci.2007.06.002.

[6] C. Fritzmann, J. Löwenberg, T. Wintgens, T. Melin, State-of-the-art of reverse osmosis desalination, Desalination. 216 (2007) 1-76. doi:10.1016/j.desal.2006.12.009.

[7] E.M. Vrijenhoek, S. Hong, M. Elimelech, Influence of membrane surface properties on initial rate of colloidal fouling of reverse osmosis and nanofiltration membranes, J. Membr. Sci. 188 (2001) 115-128. doi:10.1016/S0376-7388(01)00376-3.

[8] N. Her, G. Amy, A. Plottu-Pecheux, Y. Yoon, Identification of nanofiltration membrane foulants, Water Res. 41 (2007) 3936-47. doi:10.1016/j.watres.2007.05.015.

[9] P. Xu, J.E. Drewes, T.-U. Kim, C. Bellona, G. Amy, Effect of membrane fouling on transport of organic contaminants in NF/RO membrane applications, J. Membr. Sci. 279 (2006) 165-175. doi:10.1016/j.memsci.2005.12.001.

[10] M.T. Khan, C.-L. de O. Manes, C. Aubry, J.-P. Croue, Source water quality shaping different fouling scenarios in a full-scale desalination plant at the Red Sea, Water Res. 47 (2012) 558-568. doi:10.1016/j.watres.2012.10.017.

[11] M. Badruzzaman, A. Subramani, J. DeCarolis, W. Pearce, J.G. Jacangelo, Impacts of silica on the sustainable productivity of reverse osmosis membranes treating low-salinity brackish groundwater, Desalination. 279 (2011) 210-218.

doi:10.1016/j.desal.2011.06.013.

[12] C.J. Gabelich, W.R. Chen, T.I. Yun, B.M. Coffey, I.H. Suffet, The role of dissolved aluminum in silica chemistry for membrane processes, Desalination. 180 (2005) 307-319. doi:10.1016/j.desal.2005.02.009.

[13] V.T. Do, C.Y. Tang, M. Reinhard, J.O. Leckie, Degradation of polyamide nanofiltration and reverse osmosis membranes by hypochlorite, Environ. Sci. Technol. 46 (2012) 852859. doi:10.1021/es203090y.

[14] O. Coronell, B.J. Mariñas, D.G. Cahill, Depth heterogeneity of fully aromatic polyamide 
active layers in reverse osmosis and nanofiltration membranes, Environ. Sci. Technol. 45 (2011) 4513-4520. doi:10.1021/es200007h.

[15] E.G. Darton, RO plant experiences with high silica waters in the Canary Islands, Desalination. 124 (1999) 33-41. doi:10.1016/S0011-9164(99)00086-7.

[16] W. Song, V. Ravindran, B. Koel, M. Pirbazari, Nanofiltration of natural organic matter with $\mathrm{H}_{2} \mathrm{O}_{2} / \mathrm{UV}$ pretreatment: fouling mitigation and membrane surface characterization, J. Membr. Sci. 241 (2004) 143-160. doi:10.1016/j.memsci.2004.04.034.

[17] A. Tiraferri, Y. Kang, E.P. Giannelis, M. Elimelech, Highly hydrophilic thin-film composite forward osmosis membranes functionalized with surface-tailored nanoparticles, ACS Appl. Mater. Interfaces. 4 (2012) 5044-5053.

[18] O. Coronell, B.J. Mariñas, X. Zhang, D.G. Cahill, Quantification of functional groups and modeling of their ionization behavior in the active layer of FT30 reverse osmosis membrane, Environ. Sci. Technol. 42 (2008) 5260-5266. doi:10.1021/es8002712.

[19] B. Mi, D.G. Cahill, B.J. Mariñas, Physico-chemical integrity of nanofiltration/reverse osmosis membranes during characterization by Rutherford backscattering spectrometry, J. Membr. Sci. 291 (2007) 77-85. doi:10.1016/j.memsci.2006.12.052.

[20] T.D. Matthews, H. Yan, D.G. Cahill, O. Coronell, B.J. Mariñas, Growth dynamics of interfacially polymerized polyamide layers by diffuse reflectance spectroscopy and Rutherford backscattering spectrometry, J. Membr. Sci. 429 (2013) 71-80. doi:10.1016/j.memsci.2012.11.040.

[21] C.R. Bartels, A surface science investivation of composite membranes, J. Membr. Sci. 45 (1989) 225-245.

[22] D.G. Cahill, V. Freger, S.-Y. Kwak, Microscopy and microanalysis of reverse-osmosis and nanofiltration membranes, MRS Bull. 33 (2008) 27-32.

[23] B. Mi, O. Coronell, B.J. Mariñas, F. Watanabe, D.G. Cahill, I. Petrov, Physico-chemical characterization of NF/RO membrane active layers by Rutherford backscattering spectrometry, J. Membr. Sci. 282 (2006) 71-81. doi:10.1016/j.memsci.2006.05.015.

[24] P.J. Goodhew, J. Humphreys, R. Beanland, Electron Microscopy and Analysis, Taylor \& Francis, New York, NY, 2001.

[25] J. Goldstein, D.E. Newbury, P. Echlin, D.C. Joy, A.D. Romig Jr., C.E. Lyman, C. Fiori, E. Lifshin, Scanning electron microscopy and X-ray microanalysis, 2nd ed., Springer, New York, 1992.

[26] T. Tran, B. Bolto, S. Gray, M. Hoang, E. Ostarcevic, An autopsy study of a fouled reverse osmosis membrane element used in a brackish water treatment plant, Water Res. 41 (2007) 3915-3923. doi:10.1016/j.watres.2007.06.008.

[27] H.-C. Flemming, G. Schaule, T. Griebe, J. Schmitt, A. Tamachkiarowa, Biofouling-the Achilles heel of membrane processes, Desalination. 113 (1997) 215-225.

doi:10.1016/S0011-9164(97)00132-X. 
[28] E.M.V Hoek, M. Elimelech, Cake-enhanced concentration polarization: a new fouling mechanism for salt-rejecting membranes., Environ. Sci. Technol. 37 (2003) 5581-5588.

[29] S. Salvador Cob, C. Beaupin, B. Hofs, M.M. Nederlof, D.J.H. Harmsen, E.R. Cornelissen, F.E. Genceli Güner, G.J. Witkamp, Amorphous aluminosilicate scaling characterization in a reverse osmosis membrane, Desalin. Water Treat. 51 (2013) 936-943. doi:10.1080/19443994.2012.694202.

[30] P. Van der Heide, X-ray photoelectron spectroscopy: an introduction to principles and practices, John Wiley \& Sons, 2011.

[31] S. Mondal, S.R. Wickramasinghe, Produced water treatment by nanofiltration and reverse osmosis membranes, J. Membr. Sci. 322 (2008) 162-170. doi:10.1016/j.memsci.2008.05.039.

[32] A. Schäfer, A. Fane, T. Waite, Nanofiltration of natural organic matter: removal, fouling and the influence of multivalent ions, Desalination. 118 (1998) 109-122.

[33] Y. Mo, J. Chen, W. Xue, X. Huang, Chemical cleaning of nanofiltration membrane filtrating the effluent from a membrane bioreactor, Sep. Purif. Technol. 75 (2010) $407-$ 414. doi:10.1016/j.seppur.2010.09.011.

[34] A. Widjaya, T. Hoang, G.W. Stevens, S.E. Kentish, A comparison of commercial reverse osmosis membrane characteristics and performance under alginate fouling conditions, Sep. Purif. Technol. 89 (2012) 270-281. doi:10.1016/j.seppur.2012.01.038.

[35] C.Y. Tang, Y.-N. Kwon, J.O. Leckie, Probing the nano- and micro-scales of reverse osmosis membranes-A comprehensive characterization of physiochemical properties of uncoated and coated membranes by XPS, TEM, ATR-FTIR, and streaming potential measurements, J. Membr. Sci. 287 (2007) 146-156. doi:10.1016/j.memsci.2006.10.038.

[36] C.Y. Tang, Y.-N. Kwon, J.O. Leckie, Effect of membrane chemistry and coating layer on physiochemical properties of thin film composite polyamide RO and NF membranes I. FTIR and XPS characterization of polyamide and coating layer chemistry, Desalination. 242 (2009) 149-167. doi:10.1016/j.desal.2008.04.003.

[37] W.-K. Chu, J.W. Mayer, M.A. Nicolet, Backscattering spectrometry, Academic Press, New York, NY, 1978.

[38] A.S. Gorzalski, O. Coronell, Fouling of nanofiltration membranes in full- and bench-scale systems treating groundwater containing silica, J. Membr. Sci. 468 (2014) 349-359. doi:10.1016/j.memsci.2014.06.013.

[39] B. Mi, B.J. Mariñas, D.G. Cahill, RBS characterization of arsenic(III) partitioning from aqueous phase into the active layers of thin-film composite NF/RO membranes, Environ. Sci. Technol. 41 (2007) 3290-3295. doi: 10.1021/es062292v.

[40] J. Powell, J. Luh, O. Coronell, Amide link scission in the polyamide active layers of thinfilm composite membranes upon exposure to free chlorine: kinetics and mechanisms, Environ. Sci. Technol. 49 (2015) 12136-12144. doi:10.1021/acs.est.5b02110.

[41] A.M.S. de Jubera, Y. Gao, J.S. Moore, D.G. Cahill, B.J. Mariñas, Enhancing the 
performance of nanofiltration membranes by modifying the active layer with aramide dendrimers, Environ. Sci. Technol. 46 (2012) 9592-9599. doi:10.1021/es301392w.

[42] L. Valentino, T. Renkens, T. Maugin, J.-P. Croué, B.J. Mariñas, Changes in physicochemical and transport properties of a reverse osmosis membrane exposed to chloraminated seawater, Environ. Sci. Technol. 49 (2015) 2301-2309. doi:10.1021/es504495j.

[43] O. Coronell, M.I. González, B.J. Mariñas, D.G. Cahill, Ionization behavior, stoichiometry of association, and accessibility of functional groups in the active layers of reverse osmosis and nanofiltration membranes., Environ. Sci. Technol. 44 (2010) 6808-6814. doi:10.1021/es100891r.

[44] K. Kanaya, S. Okayama, Penetration and energy-loss theory of electrons in solid targets, J. Phys. D. Appl. Phys. 5 (1972) 43-58.

[45] L. Lin, C. Feng, R. Lopez, O. Coronell, Identifying facile and accurate methods to measure the thickness of the active layers of thin-film composite membranes - a comparison of seven characterization techniques, J. Membr. Sci. 498 (2016) 167-179.

[46] M. Mayer, SIMNRA, A simulation program for the analysis of NRA, RBS and ERDA, in: J.L. Duggan, I.L. Morgan (Eds.), Proc. 15th Int. Conf. Appl. Accel. Res. Ind. Denton, TX, Novemb. 4-7, 1998, American Institute of Physics, Melville, NY, 1998: pp. 541-544.

[47] P.J. Attayek, E.S. Meyer, L. Lin, G.C. Rich, T.B. Clegg, O. Coronell, A remotely controlled, semi-automatic target system for Rutherford backscattering spectrometry and elastic recoil detection analyses of polymeric membrane samples, Nucl. Instruments Methods Phys. Res. Sect. A Accel. Spectrometers, Detect. Assoc. Equip. 676 (2012) 2125. doi:10.1016/j.nima.2012.02.005.

[48] R. Bernstein, Y. Kaufman, V. Freger, Membrane characterization, in: E.M.V. Hoek, V.V. Tarabara (Eds.), Encyclopedia of Membrane Science and Technology, John Wiley \& Sons, Inc., 2013: p. 41.

[49] J. Goldstein, D.E. Newbury, D.C. Joy, C.E. Lyman, P. Echlin, E. Lifshin, L. Sawyer, J.R. Michael, Scanning Electron Microscopy and X-Ray Microanalysis, 3rd ed., Springer, New York, NY USA, 2003.

[50] D. Briggs, M.P. Seah, Practical Surface Analysis, Volume 1: Auger and X-ray Photoelectron Spectroscopy, John Wiley \& Sons, New York, NY USA, 1990.

[51] O. Coronell, M. ter Horst, C. Donley, Microanalysis of reverse osmosis and nanofiltration membranes, in: E.M.V. Hoek, V.V. Tarabara (Eds.), Encyclopedia of Membrane Science and Technology, John Wiley \& Sons, Inc., 2013: p. 36.

[52] T.L. Barr, Modern ESCA: The Principles and Practice of X-Ray Photoelectron Spectroscopy, CRC Press, Ann Arbor, MI, 1994.

[53] S.H. Kim, S.-Y. Kwak, T. Suzuki, Positron annihilation spectroscopic evidence to demonstrate the flux-enhancement mechanism in morphology-controlled thin-filmcomposite (TFC) membrane, Environ. Sci. Technol. 39 (2005) 1764-1770. 
[54] S. Baumann, Encyclopedia of Materials Characterization: Surfaces, Interfaces, Thin films, Butterworth-Heinemann, Greenwich, CT, 1992.

[55] L. Palmetshofer, Surface and Thin Film analysis: A Compendium of Principles, INstrumentation, and Applications, Wiley-VCH, Weinheim, 2002.

[56] H. Whitlow, M. Ostling, Surface Characterization, Wiley-VCH, Weinheim, 1997.

[57] S. Al-Jeshi, A. Neville, An investigation into the relationship between flux and roughness on RO membranes using scanning probe microscopy, Desalination. 189 (2006) 221-228. doi:10.1016/j.desal.2005.08.001.

[58] K. Boussu, B. Van der Bruggen, A. Volodin, J. Snauwaert, C. Van Haesendonck, C. Vandecasteele, Roughness and hydrophobicity studies of nanofiltration membranes using different modes of AFM., J. Colloid Interface Sci. 286 (2005) 632-8. doi:10.1016/j.jcis.2005.01.095.

[59] D.E. Newbury, N.W.M. Ritchie, Performing elemental microanalysis with high accuracy and high precision by scanning electron microscopy/silicon drift detector energydispersive X-ray spectrometry (SEM/SDD-EDS), J. Mater. Sci. 50 (2015) 493-518. doi:10.1007/s10853-014-8685-2.

[60] D.E. Newbury, N.W.M. Ritchie, Is scanning electron microscopy/energy dispersive X-ray spectrometry (SEM/EDS) quantitative?, Scanning. 35 (2013) 141-168. doi:10.1002/sca.21041.

[61] D.E. Newbury, Standardless Quantitative electron-excited X-ray microanalysis by energy-dispersive spectrometry: what is its proper role?, Microsc. Microanal. 4 (1998) 585-597. doi:10.1017/S1431927698980564.

[62] R. Lamsal, M. Chaulk, E. Zevenhuizen, M.E. Walsh, G.A. Gagnon, Integrating benchand full-scale nanofiltration testing for two surface waters, J. Water Supply Res. Technol. 61 (2012) 291. doi:10.2166/aqua.2012.089.

[63] J. Kim, F.A. DiGiano, R.D. Reardon, Autopsy of high-pressure membranes to compare effectiveness of MF and UF pretreatment in water reclamation., Water Res. 42 (2008) 697-706. doi:10.1016/j.watres.2007.08.042.

[64] A. Asatekin, S. Kang, M. Elimelech, A.M. Mayes, Anti-fouling ultrafiltration membranes containing polyacrylonitrile-graft-poly(ethylene oxide) comb copolymer additives, J. Membr. Sci. 298 (2007) 136-146. doi:10.1016/j.memsci.2007.04.011.

[65] P. Xu, J.E. Drewes, Viability of nanofiltration and ultra-low pressure reverse osmosis membranes for multi-beneficial use of methane produced water, Sep. Purif. Technol. 52 (2006) 67-76. doi:10.1016/j.seppur.2006.03.019.

[66] C.J. Harrison, Y.A. Le Gouellec, R.C. Cheng, A.E. Childress, Bench-scale testing of nanofiltration for seawater desalination, J. Environ. Eng. 133 (2007) 1004. doi:10.1061/(ASCE)0733-9372(2007)133:11(1004).

[67] M. Lee, J. Kim, Membrane autopsy to investigate $\mathrm{CaCO}_{3}$ scale formation in pilot-scale, submerged membrane bioreactor treating calcium-rich wastewater, J. Chem. Technol. 
Biotechnol. 84 (2009) 1397-1404. doi:10.1002/jctb.2195.

[68] P. Xu, C. Bellona, J.E. Drewes, Fouling of nanofiltration and reverse osmosis membranes during municipal wastewater reclamation: Membrane autopsy results from pilot-scale investigations, J. Membr. Sci. 353 (2010) 111-121. doi:10.1016/j.memsci.2010.02.037.

[69] D. Vogel, A. Simon, A.A. Alturki, B. Bilitewski, W.E. Price, L.D. Nghiem, Effects of fouling and scaling on the retention of trace organic contaminants by a nanofiltration membrane: The role of cake-enhanced concentration polarisation, Sep. Purif. Technol. 73 (2010) 256-263. doi:10.1016/j.seppur.2010.04.010.

[70] K. Chon, S.J. Kim, J. Moon, J. Cho, Combined coagulation-disk filtration process as a pretreatment of ultrafiltration and reverse osmosis membrane for wastewater reclamation: an autopsy study of a pilot plant., Water Res. 46 (2012) 1803-1816.

doi:10.1016/j.watres.2011.12.062.

[71] G. Kang, Y. Cao, Development of antifouling reverse osmosis membranes for water treatment: A review., Water Res. 46 (2012) 584-600. doi:10.1016/j.watres.2011.11.041.

[72] Y.-L. Ji, Q.-F. An, Q. Zhao, W.-D. Sun, K.-R. Lee, H.-L. Chen, et al., Novel composite nanofiltration membranes containing zwitterions with high permeate flux and improved anti-fouling performance, J. Membr. Sci. 390-391 (2012) 243-253. doi:10.1016/j.memsci.2011.11.047.

[73] S. Kwak, S. Kim, S. Kim, Hybrid Organic/Inorganic Rosmosis (RO) membrane for bactericidal anti-fouling. 1. Preparation and characterization of $\mathrm{TiO}_{2}$ nanoparticle selfassembled aromatic polyamide thin-film-composite, Environ. Sci. Technol. 35 (2001) 2388-2394. 


\section{XPS}

$\%$ atom/atom, bond signature, surface information

\section{EDS}

\%atom/atom, SEM imaging, bulk information
RBS

\%atom/atom, depth profiling capabilities

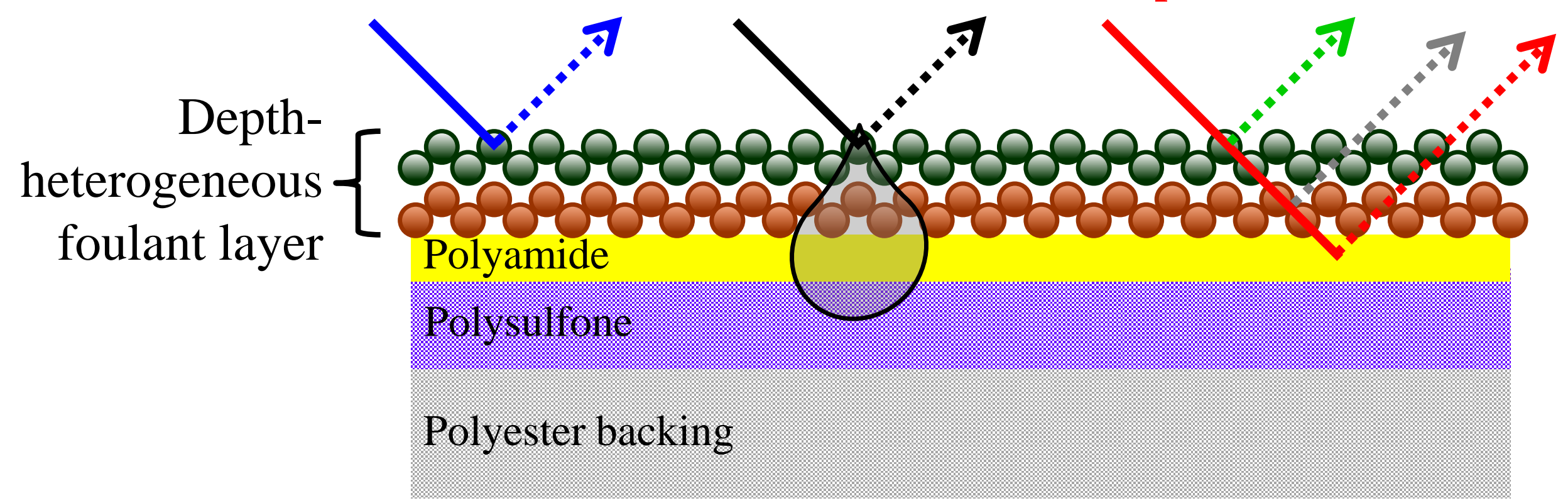

